Portland State University

PDXScholar

2-18-1976

\title{
A Descriptive Study of Thai Nonverbal Communication
}

Suriya Smutkupt

Portland State University

Follow this and additional works at: https://pdxscholar.library.pdx.edu/open_access_etds

Part of the Critical and Cultural Studies Commons, South and Southeast Asian Languages and Societies Commons, and the Speech and Rhetorical Studies Commons Let us know how access to this document benefits you.

\section{Recommended Citation}

Smutkupt, Suriya, "A Descriptive Study of Thai Nonverbal Communication" (1976). Dissertations and Theses. Paper 2587.

https://doi.org/10.15760/etd.2584

This Thesis is brought to you for free and open access. It has been accepted for inclusion in Dissertations and Theses by an authorized administrator of PDXScholar. Please contact us if we can make this document more accessible: pdxscholar@pdx.edu. 
AN ABSTRACT OF THE THESIS OF Suriya Smutkupt for the Master of Arts in Speech Communication presented February 18, 1976. Title: A Descriptive Study of Thai Nonverbal Communication: APPROVED BY MEMBERS OF THE THESIS COMMITTEE:

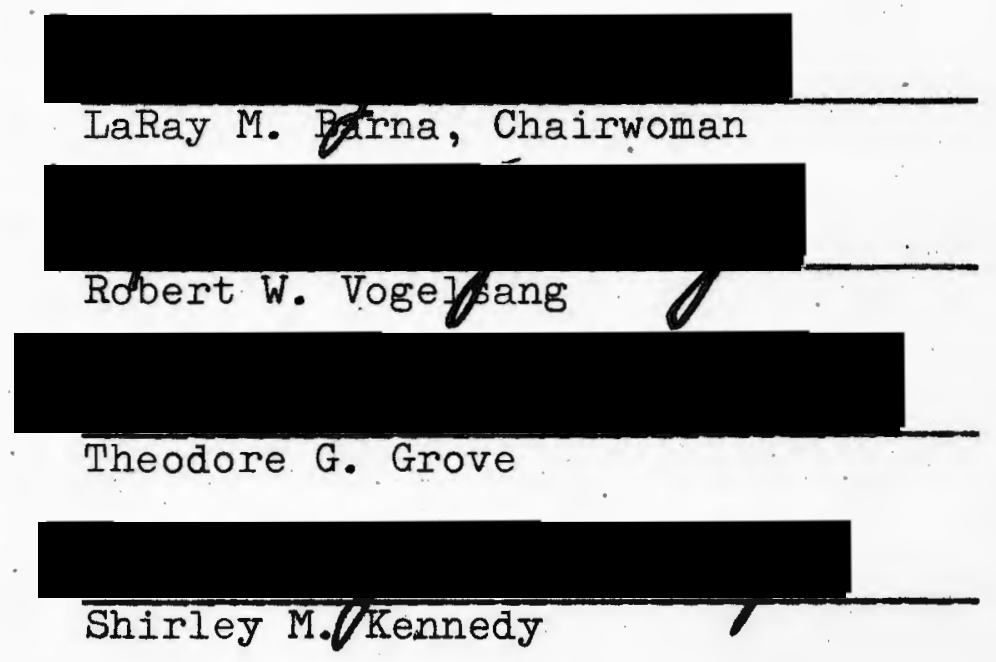

Nonverbal communication is especially significant in the area of intercultural communication. Familiar signals often signify and convey different and unexpected messages, usually out-of-awareness, and then unfamiliar stimuli cause confusion and uneasiness. This is a report of Thai NVC, which intends (I) to describe selected Thai nonverbal behavior, (2) to relate these to appropriate time and context, (3) to explain a cultural component that makes the behaviors acceptable and/or mandatory, and (4) to report 
how Thai nonverbal behaviors may affect intercultural and cross-cultural communication.

Selected Thai nonverbal messages are described:

(1) nonverbal signals: the sign language of wai, the kinesthetic behaviors of eye movement, and hand movements which include receiving, pointing, indicating farewell, rejection, negation, disagreement, beckoning, applause, counting, bad odor signal, insulting signal, and angry and friendly signals, (2) nonverbal action: the action of feet and khwan, postures which include sitting, walking, and standing, (3) object language: four religious ceremonies of lod khr2 kaaw pun, dam hua, wai khruu, and wi sa kha bu chaa; the use of artifacts: phra cee dii, phra phud tharubb, khryan raay, ta krud, (dta gkroot) and jan, colors (clothing) which includes yellow, khaki, blue, red, daily color, black and white, the material orientation to directions such as staircase positions; cooking art which includes breakfast and eating, (4) paralanguage: the Thai linguistic parallel to paralanguage, especially vocal intensity (loudness and softness), (5) personal and social distance which includes proxemic behaviors of infancy, late childhood, adolescence, and adulthood, and male and female public positions, and male and female sleeping positions (6) olfaction: artificial scents and natural body odors, and finally (7) skin sensitivity: touch and temperature. 
The method used to gather data was through participant observation. The descriptions of these illustrative Thai NVC behaviors are drawn from the writer's personal firsthand knowledge of Thai life, from Thai informants, his field work experiences as a research assistant to a Cornell University anthropologist in Thailand, from his experience as an interpreter-translator for the U.S. Army there, and his observations of Thai nonverbal behaviors among Thai migrants and students in many natural settings in the United States of America. The approach of "Participant Observation" is a social and cultural anthropological technique best described by Bruyn (1966).

The study shows that Thais are rigidly taught behaviors early in life, which portray nonverbal messages. These become a part of Thai cultural communication norms. Thus, Thais communicate through explicit and unquestioned sets of norms, using proper, desirable, and appropriate behavior for them. Since these cultural norms are taught early in life, they are out-of-awareness and deeply ingrained. Evidence is given that Thai NVC behavior is culturally interpreted. In intercultural and cross-cultural communication, this should be taken into consideration to prevent erroneous interpretation. 
A DESCRIPTIVE STUDY OF THAI NONVERBAL COMMUNICATION

$$
\text { by }
$$

SURIYA SMUTKUPT

A thesis submitted in partial fulfillment of the requirements for the degree of

\author{
MASTER OF ARTS \\ in \\ SPEECH COMMUNICATION
}

Portland State University

1976 
TO THE OFFICE OF GRADUATE STUDIES AND RESEARCH:

The members of the Committee approve the thesis of Suriya Smutkupt presented February 18, 1976.
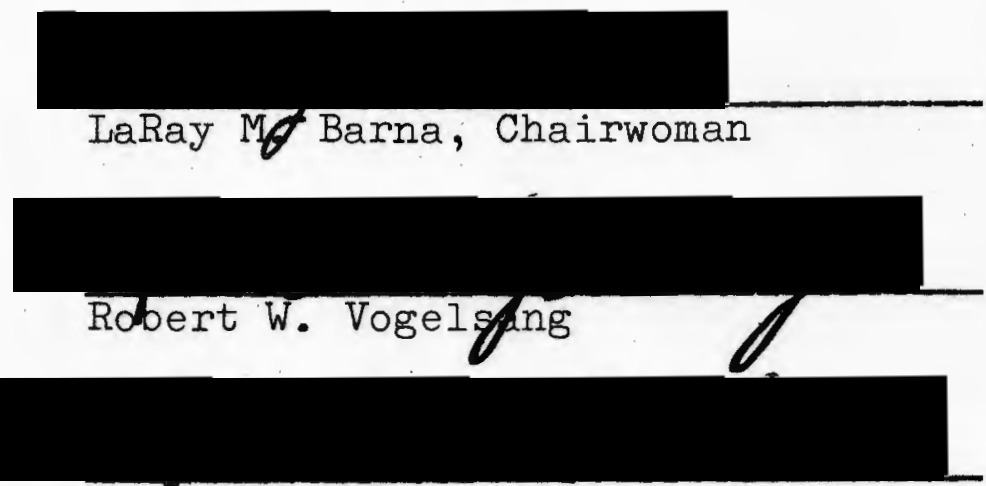

Theodore G. Grove

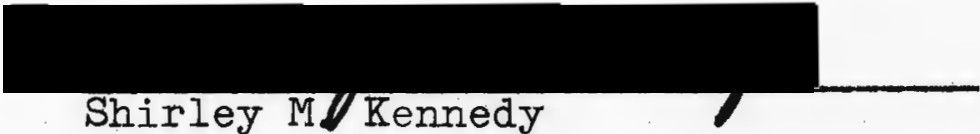

APPROVED : Robert W. Vogelsa/g, Chairmagf, Department of Speech
Communication

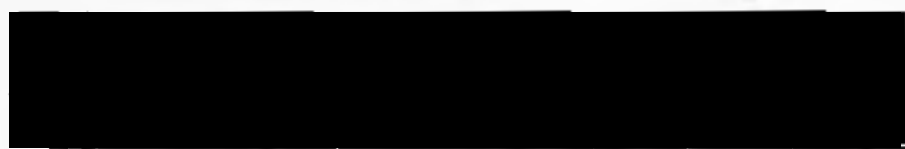

Richlard B. Halley, Acting Deanf of Graduate Studies and
Research February 27, 1976 
Dedicated to

Three American Institutions: Tacoma Community College, Pacific Iutheran University, and Portland State University where I received the academic training and some financial assistance, especially from the last two institutions.

Every American who taught me the English language which I used as the medium language in writing this thesis; and their way of life which inspired my quest to share this aspect of the Thai way of life.

And to this great country--the United States of America--that has granted me a permit to stay, to have a second home, and above all, to rediscover this aspect of my own culture. 


\section{ACKNOWLEDGMENTS}

This study was conceived in 1975, the International Women's Year, and is credited to two women, Professors Shirley M. Kennedy, Chairwoman, Department of Anthropology, and LaRay M. Barna, my committee chairwoman and graduate advisor who was on her sabbatical leave. Professor Kennedy gave me the most needed academic advice in the absence of Professor Barna who spent the first part of her sabbatical leave at the University of Minnesota, and was kind enough to resume her chairwomanship to help me on her own time upon her return to Portland. Without their help, direction, expertise, and understanding, the completion of this study would have been impossible. The other two members of my committee, Professors Theodore G. Grove and Robert W. Vogelsang--especially his assistance on my personal matters--are appreciated for their support and assistance throughout.

I would like to acknowledge the immense assistance of Professor Charles F. Keyes, Department of Anthropology, the University of Washington for his consultation and expertise on the Thai culture.

I particularly appreciate the concern of two of my graduate friends, Katy Nadal-Kato and Janet Metzger, who listened to my "laments" throughout many difficult times. 
I thank Mrs. Robert W. Vogelsang who kindly consented to type this thesis. 
TABLE OF 'CONTENTS

PAGE

ACKNOWLEDGMENTS • • . . . . . . • . . . . •

CHAPTER

I INTRODUCTION • • . . . . . . . . . . 1

Purpose ............ . . 3

Justification . . . . . . . 4 4

Method ............. 6

Organization . . . . . . . . 7

II BACKGROUND INFORMATION ON THAILAND . . . 1

Linguistic Background of the Thai Language .......... . . 14

III MESSAGE THROUGH NONVERBAL SIGNALS • . . 18

Sign Language . . . . . . . 18

Kinesic Behaviors . . . . . . . 21

IV MESSAGE THROUGH NONVERBAL ACTION • • • . 31

Action Language . . . . . . . 31

Postures . . . . . . . . 35

$V$ MESSAGE THROUGH OBJECT AND USE OF

ARTIFACTS .. . . . . . . . . 4 42

Object Language-Four Religious

Ceremonies . . . . . . . 4 42

Use of Artifacts . . . . . . . 53

Clothing (Colors) ....... . 58 
Orientation to Directions ..... 61 Cooking ............. 62

VI MESSAGE THROUGH PARALANGUAGE . . . . . 69

Thai Linguistic Parallel to Paralanguage in Thailand ...... 69

Vocal Intensity (Loudness and Softness) . . . . . . . 70

VII MESSAGE THROUGH PERSONAI AND SOCIAI DISTANCE ............. . 76 Proxemics . . . . . . . . . 76

VIII MESSAGE THROUGH OLFACTION • • • • . . . 81

IX MESSAGE THROUGH SKIN SENSITIVITY • • . • 85

$\mathrm{X}$ IMPLICATIONS . . . . . . . . . . 89

REFERENCES CITED . . . . . . . . . . . . . . 92

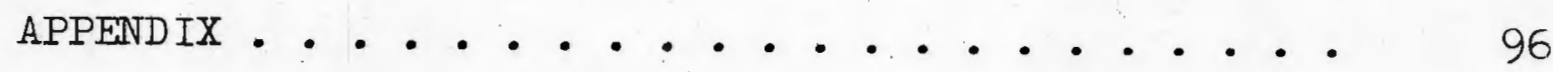




\section{CHAPTER I}

\section{INTRODUCTION}

In spite of the popularization of the subject of nonverbal communication by Fast (1970) and other nonverbal communication researchers (i.e., Ekman 1975, Scheflen, 1964), a large proportion of Westerners remain unaware of its impact.. Most students who have completed a course in basic speech communication, however, could probably quote Mehrabian's (1974) statistics that only $7 \%$ of the impact of a message comes from the verbal portion, the rest being vocal (38\%) and facial (55\%) (p. 87). Smith (1972) takes cognizance in saying, "It has been estimated that 65 percent of the social meaning of communication is carried by nonverbal communication" (p. 292). Lopez. (1973) quotes Birdwhistell's estimation that "no more than thirty or thirty-five percent of social meaning of a conversation is carried by the words" (p. 4). Singer (1975) has articulated that "There is mounting evidence that within any given group nonverbal communications may account for the overwhelming majority of the communication which occurs" (p. 20). These statistics indicate the tremendous potency of nonverbal communication and help to explain why it is of such prime importance to 
the general field of speech communication and to intercultural communication in particular. ${ }^{1}$

In the rapidly developing area of intercultural communication, NVC is perceived as very important. NVC is one of five "stumbling blocks" (Barna 1975) to intercultural communication. ${ }^{2}$ NVC is a component of all human social behavior that, although universally found is culturally or even individually variable as to meaning. Iopez (1973) has revealed:

Once these NVC behaviors--kinesic, proxemic and haptic--are understood and identified for cultures in which there is constant contact, communication can be enhanced . . . (p. 10)

Austin (1971) also said that "Intercultural confusion and misunderstanding is greater in the nonverbal modalities of communication than in the verbal . . ... (p. 148).

NVC is learned from the family and early in life. It is articulated by Malinowski (1973) who believes that:

He [the individual] is born into the family, which almost invariably supplies his earliest and most important schooling in earliest exercise of bodily functions, in learning of language, and in the acquisition of the simplest manners of cleanliness, conduct, and polite behavior ( $\mathrm{p} .284$ ).

Birdwhistell (1970) anticipates that:

- . infants from every society in the world can and do internalize the communicational system of that society in approximately the same amount of time, so that the "normal" six year old is able to move smoothly within the communication system of his society (p. 6). 
To improve intercultural communication it is obviously necessary to explore patterns of nonverbal communication that exist in different cultures as Davis (1974) says, "Every culture has its own body language, . . " (p. 93). Ruesch and Kees (1974) have also observed that "Every social group has developed systems of communication in which particular words, signs and gestures have been assigned communicative significance" (p. 192). So does Scheflen (1964) who has echoed, ". . every culture molds the raw actions according to its own tradition" ( $\mathrm{p}$. 317).

It seems that nonverbal communication patterns are similar to a language's system, therefore it could be learned like one learns a language to reduce misunderstanding in the area of intercultural communication. In the following study, the patterns of one such system, Thai NVC, will be explored.

\section{PURPOSE}

The purposes of this study are: (1) to describe selected Thai nonverbal behavior, (2) to relate these to appropriate time and context, (3) to explain a cultural component that makes the behaviors acceptable and/or mandatory, and (4) to report how. Thai nonverbal behaviors may affect intercultural and cross-cultural communication. 


\section{JUSTIFICATION}

The Thai "point of view" concerning the presence of Americans in Thailand has been widely published. It is hardly surprising that the visitors are viewed critically. But the American reader would like to discover the reasons underlying Thai disapproval. When several versions of recent antiAnerican commentary were compared, this reader was surprised to discover that the common, most damning, and universally condemned bit of behavior was credited to American soldiers, and it consisted of varied forms of body contact with Thai girls "on the streets" or in other public places. Apparently. many Thai perceive overt physical interaction as a more serious offense than our disrupting the national economy of Thailand by an avalanche of men, money, and materials!

Howell 1968, p. i.

Americans, for example, are accustomed to patting snall children (up to about the age of ten) on the head. When we meet Thais, who to us are small and doll-like, we have an almost irresistible urge to pat them on the head. Since the top to a Thai's head. is where his soul is connected with heaven, this is a "very great offense indeed. Thais never touch each other there.

Austin 1972 , p. 148.

Although researchers in the field of intercultural communication use different theories and techniques in pursuing their work, they share one commonality, and that is that the area of nonverbal communication is very important (Hal1 1959, 1966, Stewart 1972, Birdwhistell 1952, 1970, Barna 1975). NVC is a complex system, like a language, and it must be isolated and studied extensively 
from one culture to another. Such complex systems may be acquired just as when one learns another language as a second language, providing that a specific NVC system from the culture is organized and available in a systematic framework.

To the writer's knowledge this report is the first attempt to present the Thai NVC as an isolated discipline. There is no known research in this area with the exception of several term papers written by Thai students in the United States. These two unpublished term papers were "Verbal and Nonverbal Communication Patterns in Thai Social Life," written by Prakaichatra Sukhsvasti, and subsequently presented to the International Communication Association, Phoenix, Arizona, April 1971, and "Comparative Study of the American and Thai Families," by Chamnong Vilbulsri, 1967. These two papers although not available to the writer, were used as reference materials in an article, "Interpretations of Kinesics are Cultural not Universal," by Alice C. Pack, 1973. In this article, some Thai nonverbal patterns are briefly reported but with little and incomplete social and cultural implication. Nevertheless with the Thais' and other countries' evidences, Pack wrote:

In my research I have not found any single culture that has accepted universal interpretation of its own meaningful gestures. Sometimes these correlate with those of another culture, sometimes they contrast, and often they are unique (p. 9). 
With the increasing number of Thai students and immigrants entering the United States of America in the last decade, it is very important for involved parties such as American educators, to be aware of the subtle Thai NVC behaviors in order to strengthen and gain a better relationship with the Thais and vice versa. They can learn to tolerate and understand each other's idiosyncrasies in nonverbal communication. The result of this study can be incorporated in orientation programs for the future Anerican personnel who will be sent to work side by side with Thais in Thailand. Moreover it certainly can help Thais to increase their awareness and develop deeper understanding of this specific "informal" 3 pattern and aspect of their own cultural heritage. As Hall (1959) has suggested:

Once an informal [underline added] pattern has been adequately described it can then be understood by others in the same culture with almost lightning speed since it has already been learned (p. 119).

\section{METHOD}

The organizational pattern of this report is based on the work of three NVC researchers, Ruesch and Kees (1974) and Duncan (1969), as a convenient means of reporting the selected. Thai NVC behaviors. There is no intent to classify any behavior as exclusively belonging to one category and not the others. 
The approach is closer to the social and cultural anthropological method than an empirical one. It is similar to the "Participant-Observation" technique. 4 The conventional method of data gathering, that of going to the country in question with formulated research procedures, was not used, since the writer had the advantage of being instructed in the behaviors from early in life.

In addition to the writer being a.Thai, he later worked as a research assistant to a Cornell University anthropologist who was conducting research in the Chiengmai area in the preparation of a thesis for an advanced degree. 5 He worked as an interpreter-translator for the U.S. Army there. 6 In the United States he has observed Thai NVC behaviors among Thai migrants and students in Portland after the study was conceived in 1975.7 It is believed that these experiences gave him the objective and scientific approach necessary to record his observations.

\section{ORGANIZATION}

Organizational framework of this study follows the patterns set by Ruesch and Kees (1970) and Duncan (1969). Ruesch and Kees have identified three distinct categories of nonverbal communication as sign language, action language, and object language. Their descriptions are: 
Sign Language includes all those forms of codification in which words, numbers, and punctuation signs have been supplanted by gestures; these vary from the "monosyllabic" gesture of the hitchhiker to such complete systems as the language of the deaf.

Action Ianguage embraces all movements that are not used exclusively as signals. Such acts as walking and drinking, for example, have a dual function: on one hand they serve personal needs, and on the other they constitute statements to those who may perceive them.

Object Ianguage comprises all intentional and nonintentional display of material things, such as implements, machines, art objects, architectural structures, and--last but not least--the human body and whatever clothes or covers it. The embodiment of letters as they occur in books and on signs has a material substance, and this aspect of words also has to be considered as object language (p. 189).

Duncan's nonverbal modalities are:

- . (a) body motion or kinesic behavior: gestures and other body movements, including facial expression, eye movement, and posture; (b) paralanguage: voice qualities, speech nonfluencies, and such nonlanguage sounds as laughing, yawning, and grunting; (c) proxemics: use of "social and personal space and man's perception of it [Hall 1966, p. 1];

(d) affaction; (e) skin sensitivity to touch and temperature; and (f) use of artifacts, such as dress and cosmetics (p. 118).

These categories and modalities will be used as a convenient means of reporting the behaviors. Moreover there is no intent to classify any selected behavior as exclusively belonging to one category and not the other. NVC frequently partakes of several modalities simultaneously. 


\section{Chapter 1-Notes}

$I_{\text {Throughout this report the words intercultural and }}$ cross-cultural communication will be used as Harms (1973) has defined them. The differences are:

Intercultural . .

Two-way

Dyadic; small group

Mutual purpose

Unofficial

Informal

Developed message

Interdependent
Cross-cultural . .

One-way

Large group

Individual purpose

Official

Formal

Prepared message

Hierarchial (p. 41)

${ }^{2}$ Barna (1975) lists five "stumbling blocks" to intercultural communication as: (1) language, (2) nonverbal. communication, (3). perceptions and stereotypes, (4) tendency to evaluate, and (5) high anxiety (pp. 25-35).

3"Informal" is used as Hall (1959) defines it:

The informal is therefore made up of activities or mannerisms which we once learned but which are so much a part of our everyday life that they are done automatically (pp. 74-75).

${ }^{4}$ The "Participant Observation" technique as Bruyn (1966) has designed it conventional roles:

The participant observer shares in the life activities and sentiments of people in face-to-face relationships (p. 13).

The role of the participant observer requires both detachment and personal involvement ( $p .14$ ).

The participant observer is a normal part of the culture and the Iife of the people under observation (p. 15).

The scientific role of the participant observer is interdependent with his social role in the culture of the observed (p. 18).

The role of the participant observer reflects the social process of living in society ( $p .20)$. 
5 From December 1965 through October 1966, the writer worked as a research assistant to a Cornell University anthropologist who was conducting research in the Thai urban Buddhism in the Chiengmai area in the preparation of a thesis for an advanced degree. The writer was the interpreter in all extensive interviews of monks and laymen. He also researched Thai tests used as references for the anthropologist.

6 From October 1966 through December 1968, the writer worked as an interpreter-translator for the U.S. Army, 46th Special Forces Company (Airborne), Lopburi, Thailand. $\mathrm{He}$ also served as an administrative office supervisor. He was the mediator when an intercultural communication problem arose. In many instances, a problem arose from misinterpreting nonverbal behaviors. Moreover, he taught Thai to U.S. military personnel and spoken English to Thai civilian personnel.

? From December 1968 until the present, the writer has. been living and attending school in Washington and Oregon respectively. He has witnessed many instances when an intercultural communication problem occurred between an individual Thai and an American. For example, a Thai employee complains that an Anerican supervisor is too "bossy." "When the Thai is asked for a specific reason for labeling the supervisor, his reply always is, "Because the supervisor speaks loudly and with grave tone of voice." After the study was conceived, the writer paid more attention in observing Thai NVC behaviors among the Thai migrants and students in formal and informal settings. For example, one Thai informant told the writer that while the Thai governor of Chiengmai was at the Portland Hilton lounge, he stopped visiting Thai students from sitting on the floor in his presence. They automatically behaved as if they were back in Thailand where the action would be proper. They avoided sitting face to face with the governor who was in a higher social status, that is, being a government official and also being an elder. The governor saved an intercultural mishap because unknowing Anericans would have interpreted the Thai practice of sitting on the floor of a junior in the presence of a senior person otherwise.

Most of the data have been rechecked with Thai informants through many personal interviews. One religious rite was observed and participated in by the writer. A group of Thai Buddhist monks from Thailand and Wat Thai, Los Angeles, came to perform a rite to a sick Thai migrant who is a Portland resident. The writer also attended a formal lecture delivering to all Thai attendants, given by one high ranking monk. 


\title{
CHAPTER II
}

\author{
BACKGROUND INFORMATION ON THAILAND
}

\section{THAI SOCIAL STRUCTURE}

The social structure is that important system of elements which lasts and which everybody takes account of.

$$
\text { Redfield 1973, p. } 42 .
$$

Social structure is... the entire culture of a given people handled in a special frame of theory.

$$
\text { Fortes 1953, p. } 21 .
$$

Past

Since the birth of the country, Thailand has been ruled by many monarchs. From the Nan Caw era (c. A.D. 6501258) to the Bangkok era (1767-1932), Thailand was under the absolute monarchy system. The system of constitutional monarchy began in 1932 and has continued until the present time. Thai social structure which emphasizes hierarchy and vertical relationships among Thais, strongly influences this system (Smith et al. 1968).

The monarchs lived in the capital city which was the center of commercial and political affairs. The governing bodies consisted of the most privileged groups. They were 
the monarchs' representatives in governing the rural people who constituted the majority of the total population.

Iife among the rural Thais was centered in their

families and the Buddhist monasteries, both of which also emphasized a hierarchical framework. Thus in both secular and nonsecular relationship hierarchy dominated. Seniority in ranks, sex, and age, played the most significant role in such a hierarchical and vertical system.

The local Buddhist monastery and one's family were the institutions the person was close to. Males were educated by Buddhist monks at monasteries. Buddhist monks also practiced folk medicine due to the lack of hospitals. People supported the monasteries by supplying all the monks their immediate necessities. Monasteries were used as a social and political gathering place for the community.

\section{Thai Family System}

The Thai family structure is a structure of vertical organization. It consists of superordinates and subordinates. Thus, seniority figures prominently. in Thai families. The communication process is one-way communication.

There are two types of family: nuclear family and extended family. A nuclear family consists of a married couple and usually with a few close relatives. An extended family is more common and consists of a married couple with many kinfolks of the couple. 
The vertical and hierarchical character is taught and expressed. Kinship terminology is used to convey this character. A junior must address a senior with a proper kinship term which conveys the family's character of vertical and hierarchical form. Moreover, manners must be "proper and appropriate."

\section{Present}

Since the constitutional monarchy began in 1932, many changes have occurred, but two institutions--the family and religion, especially Buddhist monks and monasteries in the rural Thai. society where the majority of Thais live--have remained. Buddhist monks and Buddhist practice are major influences on the Thais' behavior and personality.

Thai society is composed of rural and indigenous farmland which belongs to small-scale independent farmers whose lives still center around their families and local monasteries. They maintain their close relationships with Buddhist monks even though the latter are no longer responsible for the farmers' secular education. Due to the closeness of these two institutions, Buddhism as the moral resource, provides a moral code for all thais. In a community if one is known as a "good" person, it implies that he also is a "good" Buddhist. Silth et al. (1968) has observed, "A villager who is generous and tolerant and who excels in Buddhist virtue is more highly respected in his community than the wealthy farmer who has few or none of these qualities" (p. 116). 
Thai social structure continues as a vertical and hierarchical system which consists of superordinates and subordinates. Monarchy, Buddhism, and family are still the dominate parts in this society. This fact stands for both Thai urban and rural societies. Its communication process is the one-way communication. Subordinates are like children: sometimes "they are seen but not heard." Moreover, seniority has a permanent place in Thai society.

\section{LINGUISTIC BACKGROUND OF THE THAI LANGUAGE}

Historically, the Thai people established their very first kingdom at Naan Caaw ( นาน 12 ), the earliest known Thai state (in Yunnan, China), decades prior to the thirteenth century. ${ }^{1}$ While they were being forced to migrate southward, their first capital was founded within the border of the present Thailand territory at sukhoo thai ( northwest. The Thai language (spoken) was historically mentioned in the Chinese annals more than two thousand years ago. Once Sukhoo thai, the first capital, was founded, the earliest linguistic record of the written language emerged. During the reign of King Raam khamhery (572คㄱㄴㅐ ), one of several reigning kings of this period, the original Thai characters were invented. From what origin the king derived these characters is unknown. However, the characteristics of the letters resemble the first knowm Mon and Khmer 
characters which originated in the southern part of India and were widely used throughout the mainland of Southeast Asia. Not until King Lyy thai (Ẩ) (nes), King rama-khamhang's one, began to reign, were Thai characters completely improvised. They are called "standard Thai," and consist of 44 characters and approximately 38 vowel and diphthong forms. 2

Standard Thai is spoken by approximately 36 million of the peoples who inhabit Thailand. It is divided into five major dialects: (1) Standard Thai, (2) Khum Lao dialect, (3) Khum Meung dialect, (4). Dtam-Preu dialect, and (5) Korat dialect. 3

The relationship of the Thai language to other language families is unclear. Iinguists used to have the notion that it belonged to the large Sino-Tibetan linguistic family--the Chinese-Tai branch. However, the proof is nebulous. A recent linguistic study is inclined to place the Thai language in a family of Tai-Kadai languages (Smith et al. 1968).

The Thai language is a tonal, uninflected language which originally and predominately consists of monosyllabic words, but unanalyzeable polysyllabic words also occur (Hass 1964). To compare these tones with pitch in English, they are: (1) sia saaman, the middle (common) tone, shown with no tonal mark in the Thai writing system and equivalent 
to a normal pitch in English, (2) sian?eeg, the low tone ( ), shown with maj?eeg (1), the first tonal marker of the Thai writing system and equivalent to a lower pitch and a normal pitch in English, (3) siaythoo, the falling (dropping) tone $(\boldsymbol{\Lambda})$, shown with majthoo $(\boldsymbol{\nu})$, the second tonal marker of the Thai writing system and equivalent to a falling pitch in English (4) siantrii, the high tone (1), shown with maithrii (o), the third tonal marker of the Thai writing system and equivalent to a higher pitch than a normal pitch, and (5) siancadtawaa, the rising tone ( $\boldsymbol{V}$ ), shown with majcadtawaa $(+)$, the fourth tonal marker of the Thai writing system and equivalent to a pitch of questioning or surprise in English.

The Thai morphology is restricted to derivation since the language makes no use of inflection like English does (Hass 1964). Thai words are uninflected, that is, they do not carry any grammatical function as in English. The grammatical functions are indicated by the derivation. The Thai syntax is similar to English. A Thai sentence normally consists of subject, verb, and object, respectively. Throughout this text, Hass' (1964) phonetic symbols are used but without the five tonal markers. A legend on the transliteration of Thai will be found in the Appendix. 


\section{Chapter 2-Notes}

IThe Thai historical setting according to Smith et al. (1968):

The Nanchao Era

The Sukhothai Era

The Ayutthaya Era

The Bangkok Era

The Constitutional Era

(c. A.D. $650-1258)$

(c. 1350-1767)

$(1767-1932)$

(1932-

(p. $x i)$

2 There is a discrepancy on the number of vowel and diphthong forms. Area Handbook For Thailand (1963, 1971) by Harvey H. Smith et al., records that there are 28 vowel and diphthong forms. The Fundamentals of the Thai Language (1957) by $\mathrm{S}$. Campbell and C. Shaweevongse, indicates that there are 38 vowel and diphthong forms. This number is included from the inherent vowels and the combination of consonant-vowel. Thai (1970) by W. G. Yates and O. Tryson, shows that there are 35 vowel and diphthong forms.

${ }^{3}$ Standard Thai is the official written and spoken language. It is the national language. Khum Lao is a spoken language and is used in the northeastern vicinity. Khum Myang is a written and spoken language and is used in the northern area. Its written form is almost vanished. but not the spoken language which is used daily. Dtam-preu is used in the southern area. It is a spoken language. The word Dtam-preu denotes an offensive connotation to the local people. It is known as Pag taaj (whifh) language. 
CHAPIER III

\section{MESSAGE THROUGH NONVERBAL SIGNATS}

\section{SIGN IANGUAGE}

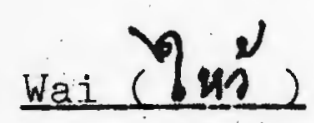

To illustrate the Ruesch and Kees category of sign language, one well-known and distinctively Thai nonverbal phrase has been chosen. This is known as wai (waai). 1 Wa is rigorously taught to every child as soon as it is Greting able to comprehend verbal communication. This gesture of obeisance is the first formal nonverbal teaching that the child in Thailand receives (Benedict 1952, Phillips 1974). A mother holaing her infant in her arms puts its palms together between her own and raises them to the chin or to the forehead, according to the degree of deference that is called for. Before a child is taken from the house, its hands will be put in proper position to greet guests, and when the mother takes it to the temple she raises its palms still higher and flattens them on the floor--to pay homage to Budaha and the Buddhist monks. Throughout childhood it is constantly directed to wai in every appropriate occasion until it becomes a regular component of behavior. The child also absorbs or imitates this behavioral norm from the grown-ups around him. 
The nonverbal communication wai is performed to indicate greeting, bid farewell, and show deep and sincere respect and appreciation. Normally, it is the most common nonverbal communication in the inner family circle as well as in public. Children never fail to wai the family's elders, grandparents, parents, uncles, aunts, and the like before leaving for school in the morning. ${ }^{2}$. In the classroom they begin their lessons by standing up and performing the wai upon their teacher's arrival. They pay their homage to Buddha with chanting while they are maintaining this position. Their daily lessons end with the wai to bid farewell and thank their teacher. Upon their arrival at home they immediately locate all the elders and greet them all with the (6) i. In some of the orthodox Buddhist families, everyone in the family performs the wai together with a particular kind of chanting after finishing every meal. ${ }^{3}$ Finally, the daily activities end with paying homage to Buddha by performing the wai and a specific chant in front of the family's altar of the Budaha image. Wrmally three fragrant incense sticks will be lit and presented along with some fresh flowers which are an object language in addition to the sign language of the wai. ${ }^{4}$

When one passes a Buddhist monastery which houses a weli-known Buddha image or a relic of Buddha, one automatically performs the wai. 5 In General, the wai is practiced 
among people in public as a norm like handshaking or uttering "Thank you" is practiced among Westerners. In the case of an introduction, normally a person who is younger or of lower socio-economic status will perform the wai automatically, and usually his counterpart will also respond with the same wai.

The proper position for the wai is placing the palms of both hands together vertically, holding them slightly under the chin, and performing a slight head bow, chin toward the fingertips. Verbal utterances rarely accompany this act, nor does eye contact. The wai is also performed in an even more intensive way. It is called the kraab ( To kraab is to drop to ones knees in obeisance while the hands are maintaining the wai position on the forehead and the head bow is deepened to a bow from the midback. Some Thais prefer to flatten the palms on the floor; the forehead touches against the hands three times to pay homage to Buddha and only once to pay respect to Buddhist monks, the King and queen, the royal family, and parents.

When Westerners visit Thailand unless they are in Bangkok or a place where cultural norms of the West are observed they may be uncomfortable with the wai and kraab and the absence of the handshake. Even though this different behavior is accepted as "the custom" there usually seems to be a lingering, vague feeling of confusion and/or perhaps a 
such conscious rejection of the usees. There is the strain of not knowing how to respond to the wai and kraab. Should the visitor try to adopt this behavior and look and feel foolish? Should he go ahead and extend the right hand as usual? Should he just stand there and grin? Or what?

\section{KINESIC BEHAVIORS}

Actions speak louder than words.

$$
\text { Sapir 1946, p. } 19 .
$$

Illustrations from Thai culture will be made in terms of the following: (1) eye movement, (2) hand movements-receiving, pointing, farewell (rejection, negation, disagreement, beckoning), applause, counting, bad odor signal, insulting signal, and angry and friendly signal.

\section{Exe Movement}

With downcast eyes, not loitering, With guarded senses, warded thoughts, With mind that festers not, nor burns, Fare lonely as rhinoceros:

$$
\text { Conze 1971, p. } 81 .
$$

Among Thai Buddhist monks eye contact must be restrained according to the monastic rules which are faithfully observed. Accordingly, "downcast eyes" are a mannerism that is dominant in the communication process among Thais. Laymen are also influenced by this behavior because Thai 
Buddhist monasteries were and still are the "core" of Thai society and life. Ninety per cent of the total population is Buddhist. Vital social forces are centered at Buddhist monasteries which are located on every street throughout the country. Therefore eye contact is absent and has no significance in daily communication.

"Bowncast eyes" are practiced among monks who must live in an ascetic or nonmaterialistic world in which being content in a simple life style and free from any anxiety is a preferrable goal to accomplish and can be achieved by restraining one's visual contact. Practitioners take these fundamental steps and aim to enter to the ultimate path which leads them on to the right way to live according to Buddhist teachings. tho show respect and manners and humbleness, children are taught strictly to maintain no eye contact with parents, elders, teachers, and government officials when they are being spoken to. Eye contact is clearly not an essence of the Thai communication process./

"Downcast eyes" has been a part of Thai behavior as far back as the birth of the Thai nation under the various absolute monarchs. Their laws, kod monthian baan (กฏมนเทีผรบาล), laws pertaining to royalty, were promulgated in 1459. One law which related to communication stated that all the Thai subjects must practice prostration in the presence of the King, Queen, and their royal children. They 
must not look up at them. To violate any of these laws was a crime punishable only by death. These two laws were not abolished until the young Chulalongkorn, one of King Mongkut's sons whose reign marked the beginning of Western civilization in Thailand, was crowned in the nineteenth century. King Mongkut is the subject of the musical film, The King and I. Thais no longer prostrate and are free to look at the King, Queen, and their royal children. Nevertheless, to show respect and appropriate mannerism, they maintain no eye contact in their presence nor do. they maintain eye contact in the communication process. Thus the law has become a permanent informal behavior pattern that has been passed along through generations.

Erven this informal behavior Thais practice very little if no eye contact in the intracultural and intercultural communication process. Since eye contact is a very essential component in the Western communication process but not to the Thais', both parties, Thais and Westerners, must understand this cultural difference and modify their eye contact behavior in their communication in order to tolerate this idiosyncracy and to achieve a better level of success in their communication.

\section{Hand Movements:}

Receiving. The right hand is the only proper hand to receive. A child is taught early in life that it must 
extend the right hand to receive, not the left one. If it extends the left hand to receive, it will not get what it expects until it stretches out the right hand. Once the child is able to eat by itself, it is strictly trained to use the right hand. Publicly, when a reward or a diploma is conferred, a Thai must receive it with the right hand while the left hand is held under the right elbow. ${ }^{6}$ This position is maintained whenever a Thai receives something from a teacher, an elder, a monk, and other persons like these. All Thai college graduates adopt this receiving gesture when they receive their diplomas from the King and Queen, or Prince and Princess, who sometimes preside over the graduation ceremony in the absence of their royal parents. Thais also adopt and practice sincerely this receiving position in other circumstances. Normally, a person who is younger and/or in lower socio-economic status always adopts this gesture because it is the most proper and appropriate cultural behavior.

\section{Pointing. In all circumstances, the right index}

finger only is used to point, such as, to point at the blackboard in a clasșroom, and to point at other objects. The index finger is called niw chii (น̂े)-niw, finger; chii, to point. It is extended out with the rest of the fingers face down and forming a tight fist. When a Thai is angry in an argument, he maintains the pointing gesture except that the index finger and fist are turned sideways, and then he 
shakes his index finger vigorously and vertically. Parents always adopt this gesture when they scold or wish to emphasize their points to their children. As seen in a market, for example, the people involved adopt this gesture, but make it even more forceful by placing their left hands (the area between the index and thumb) on their waists. In this situation the taw-sa?ew (เที้สม position denotes that an individual is emotionally disturbed and is ready to go through the verbal battle. Sometimes, when one thinks they have outdone one's peers and wishes to tease them, this gesture is performed with a friendly smile.

Farewe 1: Rejection, Negation. Disagreement, Beckoning. When. Thais wave "goodbye" they place their right hands in a vertical position with their palms facing out and move the forearm harizontally. If this gesture is performed during an argument, it may indicate "no," "disagreement," or "rejection." The Thai gesture for "come here" is similar to that for "go away" to Americans. It is performed with the open palm moving upward and downward repeatedly. According to a well-known legend told in Thailand, a lady made this "come here" gesture famous. The gesture is called kwag myy (กวักต้ว).

Naankwag (a7vmin). Nagykwag is a lady statuette, sitting with both legs folded back to one side and with her stretching right hand in the Thai "come here" gesture. She is recognized as a charm to bring in all good omens and 
especially material wealth, like money, to her holder. She comes in various sizes, for example, a big size that must be put in a fixed platform or a small size that one can carry in a shirt pocket. She can be made out of metal, such as gold, silver, brass, or bronze; and sometimes, she is painted on a square piece of white, yellow, or red cloth. Besides her famous replica, the square cloth is inscribed with magical numbers and letters. In a house, she is put on a platform, hanging above the main front door. But more frequently, she is found in a cashbox belonging to every merchant in a Thai open market. It is a strong belief among these people that naykwag is the luckiest lady who always brings her holder good fortune.

Applause. The Thai clapping gesture is similar to the American one. It is performed with fingers tightened together, both hands are slightly crossed, and most usually in the vertical position. The elbows rest close by the sides. Thais clap with hands just below the chin. This signifies acceptance and appreciation.

Counting. Thais count from one to ten by using the right index finger and start by touching the little finger of the left hand with open palm up and each adjoining finger sequentially up to five. They then reverse the process to reach ten. When they count as in this situation, they use both index fingers, the right one as the first indicator and the left one as the other indicator. 
If Thais have to count more than ten, they do it by using the tip of the thumb to move springily from the top phalange of the little finger, the ring finger, and until they reach the low phalange of the thumb, first with the right hand and then the left. Normally, hands are in the open palm position.

Bad Odor Signal. When Thais smell a bad odor they nonverbally send a message instead of verbally expressing their thought. They vigorously wave their vertical right hand horizontally in front of their nose.

Insulting Signal. In Thailand, a circled thumb and index finger gesture denotes a female sexual organ rather than "zero," or "OK" as in America, or money as in Japan. If the other index finger is inserted outwardly, the gesture becomes an insulting sign of coitus and is used by men only in a verbal battle aiming to attack and/or embarrass one's opponent. Sometimes it can be recognized among children, especially boys when they fight or tease each other. The gesture is rarely used among adults except in the described circumstance.

Sometimes, boys insert their thumbs between their index and third (middle) fingers when their hands are in a fist form, fingers up. The gesture denotes the female sexual organ, specifically the clitoris. Again, it is used more often among males, both adults and children, as a gesture of an insult when they fight (verbally) or tease each other. 


\section{Angry and Friendly Signal. All of the nonverbal}

researchers have observed that children in every culture develop nonverbal codes at an early stage in life (Hall, Birdwhistell, Fast, Davis). Sometimes, a certain nonverbal code has a short life and lasts only throughout childhood. A unique Thai hand gesture can be used to illustrate this. Thai children, like children from other countries, get angry at each other very often in their daily communication." When they do, they normally do not express their anger verbally because they are strictly taught that a "well mannered" or a "good" person must control his emotional behaviors, such as anger. Instead they adopt a simple mutual hand signal as an innuendo, which is used popularly among Thai children. They vertically form both hands (sometimes only one hand) into fists, fingers up but with unfolded thumbs pointing towards one's opponent. The suspension of their friendly relationship takes effect immediately after the signal is emitted. Verbal utterances rarely accompany this signal, however occasionally a colloquial word for thumb, poon (ซึ), is heard accompanying the gesture. Children seem to possess skillful diplomatic talents in normalizing their ephemeral relationships. Among Thai children, another hand gesture is emitted to normalize their friendship. Iittle fingers are implemented instead of thumbs. Their vertical fists with extended little fingers pointing towards their counterparts emerge as a "goodwill" 
or "peace" gesture. Again verbal expression is absent; so is eye contact. Sometimes, a mutual friend who acts as a mediator, coheres both parties to perform an act of

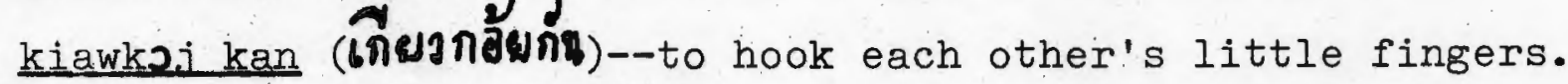
Their normal relationship resumes after this final rite of reconciliation is performed. 


\section{Chapter 3--Notes}

$I_{\text {Wai }}\left(Y \mathrm{HV}^{ل}\right.$ ) is written waaj sometimes and is used interchangeably as a verb and noun.

Kraab (గ̧९น): to prostrate oneself (in obeisance). The palms are pressed together [some Thais prefer to flatten the palms on the floor three times to pay homage to Buddha and only once to pay respect to Budahist monks, the King and Queen, the royal family, and parents]. (Hass 1972.)

${ }^{2}$ A Thai family like the writer's is an extended family.

3 This practice is absent among the immediate members of the author's family, however, a brother-in-law's aunt, who spends most of her time with the family, performs this ritual individually after every meal.

"The number "three (3)" of the incense-sticks signify "the three gems (Buddha, his teaching, his disciples)" (Hass, 1972). Fresh flowers are optional although the author's mother often uses some when she performs this ritual nightly before retiring. In this specific task one has to kraab (see footnote 1) three times to conclude the ritual.

5 This is done by all Thais (including the author) every time they pass by the Royal Monastery in Bangkok in which the famous Buddha image, the Emerald Budda, is enshrined. Not knowing the significance of this behavior, Western tourists express surprise and usually ridicule the behavior as being absurd.

${ }^{6}$ Phillips (1974) offered no description of "proper positions for hand" in this situation. However, in a reversed situation, he wrote:

- . the youngster who will actually serve the refreshment will make sure that it is on a coaster and that his hands are in the proper ritual position when he offers the arink to the guest. (p. 69) 
CHAPTER IV

MESSAGE THROUGH NONVERBAI ACTION

\section{ACTION IUANGUAGE}

"Action Language" refers to all bodily movements that are not consciously meant to communicate, but nevertheless do.

$$
\text { Smith 1972, p. } 293 .
$$

The Action of Feet and Khwan (Vỏ

In Thailand an emphasis is placed on feet. In general, almost all Westerners like to cross their legs while sitting on a chair. They are not usually aware of the direction in which their crossing top foot is pointed. When a Westerner has to deal with an old-fashioned Thai, the former may happen to have his top foot pointed at the native, who will be upset and offended. If it occurs while business is being discussed the deal can very well be called off.. If it is just a casual circumstance, there can be no potentially healthy relationship between the two. This, of course, will never be revealed or expressed verbally, but is commonly understood among the natives.

The crucial significance of this behavior is that Thais consider feet as the most rejected and lowest bodily component. Pointing out something by a foot is absolutely 
the worst social crime that one ever may commit. If you wish to suspend a relationship with a Thai, all that needs to be done is to point something out to him by using one of the feet. When the author associates with his American friends and acquaintances, his face turns red, but without anger, when he encounters this act. This is because he is fully aware that his American counterparts lack understanding of the Thai implication. Nevertheless, he fails to stop blushing. If this gesture is performed by a Thai, a fight between the two would probably seem to be inevitable. In a Thai verbal battle an opponent's face is normally compared with his attacker's heel or vice versa. This is the most insulting verbal expression possible. To avoid this, Thais use only the right index finger, lips, eyes, and chin to point.

There is a nonverbal ritual that occurs regularly. It is called dornkhaw (ดคนเข่)--"knee walk." Do2nkhaw is performed strictly in the following manner: (1) one must sit on the floor on the knees with erect torso and loose hands by the sides, (2) the person moves forward and backward on the knees within a comfortable step, and (3) the hands can be swung while moving but as little as possible. For example, if a young person needs to walk through or pass in front of a group of older people who are talking and sitting on the floor in a room, he may drop to his knees to assume the dennkhaw position. This is because of the 
seniority practice, as stated in a Thai saying: "A child should not walk by adults" heads." The head is considered to be the highest and the most respectful bodily component and no one should be above its level. Therefore, to show his appropriate manners and to pay his respect, the junior person's body must be lower than the senior person's head. Also, it is inappropriate to allow one's shadow to fall on an individual's head, one's sacred sanctuary. Ohe does not walk higher or look over senior people's heads, a practice which seems awkward, uncomfortable, and slightly ridiculous to most Westerners. But the Thais have practiced this custom for a long, long time and accept it as a means of being polite and of showing respect.

4 Another example of "action language" that would carry an unintended meaning for a Westerner is head touching. Head touching is forbidden in Laos as well as in Thailand. Stewart (1971) reveals that you dare not pat a child on the head in Laos. In Thailand, Phya Anuman Rajdhon (1961) explained by noting that khwan, the whorl (or cowlick if you prefer) the hair on top of the head, is interpreted as the locus of an individual's soul, spirit, morale, or life force. A child's khwan is not strong enough to be touched, therefore, he has a tendency to become ill if he is patted. Throughout his childhood his khwan is guarded as the precious bodily component. This cultural concept is directly and constantly taught to every child. 
Consequently, the head where one's khwan exists is guarded with one's life. If a child is patted on the head it is believed that subsequently bed wetting or nightmares may occur. ${ }^{I}$ As a child grows up feelings about guarding the head, the sacred sanctuary, grow stronger. One easily loses a friend if he touches the friend's head, even unintentionally sometimes.

Although the author is Americanized to a certain extent, his Thai nature returns when something like this happens to him. One time an American girlfriend tried to touch his head while they were eating in the school cafeteria. His immediate, automatic, and natural reaction was to jerk his head away. He then blushed crimson for at least five minutes. It was clearly noticeable and eventually the girl received an explanation of the event which had just occurred. She apologized sincerely and vowed not to make any more attempts like that. It was very difficult to explain to her that there was no anger at what she had done. The above is just one example which illustrates that one cannot go "native" all the way, as Powdermaker (1966), an American anthropologist states. No matter how Americanized we from Thailand become, we are still Thais at certain crucial moments. The same can probably be said for persons from any culture. 


\section{POSTURES}

\section{Sitting}

- . there are other significant cultural markers of nonverbal communication, perceptible in myriad body macro- and micro-signals such as manner of sitting, way of shifting position, or protocol of using eye contact.

Condon 1973, p. 6.

Cross-legged he floats along like a bird on the wing.

Conze 1971, p. 126.

Generally, the two formal and proper Thai sitting positions are unisex. When sitting on the floor on informal occasions, Thai males and females do not sit in sex specified positions but there is for both an absence of direct eye contact as it was previously explained (see Eye Movement). They have been trained since their childhood to sit in a certain position on formal occasions. Males normally sit with their knees apart and legs crossed under. (This is the sitting position which Buddha was maintaining when he obtained Nirvana over 2500 years ago.) Sometimes females adopt this position when they sit in private but not in public because it is considered inappropriate and unladylike. In the formal position males shift their legs when the legs feel tired. Their torsos must be erect and their eyes must look down on the floor in front. Hence, the protocol of 
using eye contact is absent. Thai males sit in this position when they receive guests at home, eat their meals, pay homage to Buddha and practice meditation. They also maintain this posture when they attend a religious service in a chapel at a monastery. It is also acceptable for males to sit with both legs folded back to one side and with one of the arms, the arm which is on the side of the folded legs, resting with flattened palm down on the floor. This is, technically, the formal female position.

All Thai women sit with both legs folded back to one side. This is believed to be the most appropriate sitting manner for ladies. They shift their legs as often as they like, but if they do it too often, they are critically judged as ill-mannered persons. Since they are strictly trained to sit in this position when they are quite young, they are able to maintain the position for a long time comfortably.

Buddhist monks adopt both sitting positions. Normally, when they perform a religious service, they sit with both legs folded back to one side and with their honorific fans facing the congregation. Thus, the fans block their view of the congregation, and therefore eye contact is absent. When the service is over, monks and congregation still maintain their formal sitting positions but are free to let their eyes move about the room. When practicing meditation, monks and laymen adopt both sitting positions, knees apart 
and legs crossed under, and with both legs folded back to one side.

Buddha is recognized as the greatest teacher and as such he also must have created these sitting positions, which have been adopted by all Thai Buddhists. Thais are convinced of the correctness of this interpretation and have been using these sitting positions for centuries. The positions are rigidly taught and observed and have become one of the most distinctive Thai characteristics.

\section{Walking}

Then let him loiter not, but eyes downcast, Be ever bent on musing, much awake; Then let him strive for poise, intent-of-self Cut doubt and hankering and fretful ways.

Conze 1971, p. 78.

With downcast eyes, not loitering, With guarded senses warded thoughts, With mind that festers not, nor burns, Fare lonely as rhinoceros.

$$
\text { Conze 1971, p. } 81
$$

At dawn throughout the streets of Thai cities, towns, and villages alike, a line of saffron-robed Buddhist monks with their alms bowls can be seen making their daily round to allow people to acquire merits by offering them their daily food. Robes cover their entire bodies except their heads, hands, and feet. They dress themselves according to 
the Buddhist dress code when thus appearing in public. There is very little shoulder and arm movement while they are walking solemnly in a straight line. With slow and even steps, they put their body weight on their toes; their entire bodies lean forward; their shoulders hunch forward; their heads bow slightly; and their eyes gaze a few steps ahead on the ground. This is the proper Thai Buddhist monks' walking gait, which is also adopted by the majority of Thais as the most proper way to walk. 2

Children are taught how to walk properly when they start to walk. However, Thais females are more strictly watched and guided in this than males. They must put their body weight on their toes, walk slowly, and not make any kind of commotion. In case they violate this rigid cultural norm, walking loudly, their ankles are liable to be knocked, and then there is a long lecture: on how to walk properly. They also may receive a stern scolding or ridicule: "You walk like your water buffalo has disappeared," (เดินเหผึ้ว ควาผkid d22n--to walk, myan--to be like, khwaaj--water buffalo, haaj--to disappear), and a stronger remark, especially for females, "You walk like a kicking horse," (เดินเหมื่วนม้าก้ดกริหลก dazn--to walk, myan--to be like, maa--horse, diid--to kick, e.g., jerk sidewise, of a horse, kaloog--skull). The cultural implication of the first saying is that Thai farmers value a water buffalo, the backbone in the Thai rice farming; and without it the rice fields 
cannot be ploughed and planted. Therefore it is a matter of life and death for a Thai farmer if one of his water buffalo disappears! Thais rarely walk in this manner. As for the second remark, Thais do not conceive like Americans do that horses walk gracefully. They envisage that horses always gallop, not walk. Therefore, they associate the horse galloping with "ill-mannered" behavior.

The rational and logical interpretation of this cultural walking norm may be simple--to live peacefully and to make the wooden or bamboo floor last longer. An ordinary house belonging to a Thai middle class person is made of wood, and most Thai farmers' houses are made of bamboo. The bamboo used. for a house floor has a very large trunk, 10 to 12 inches in diameter, which is slashed in order to have it evenly spread as a floor. Therefore, it is not very strong. (With these types of floor, an inhabitant cannot walk loudly.) Thais also believe that loud commotions always chase away all good omens for which every Thai householder yearns. Thus they must try to make no noise or as little noise as possible to lure all good luck and omens into their homes. With little or no commotion to damage the wooden or bamboo floor, a house is normally in a better condition and stands a better chance of longer survival. Also, its Thai inhabitants are able to live peacefully after a long, hard day of work. 
Standing ${ }^{3}$

Thais in formal situations stand with their bodies leaning slightly forward; their heads slightly bowed, their eyes downcast in front, their shoulders slightly hunched, and their hands interlocked and hanging loosely in front of them. They maintain this posture when they speak to the King and Queen, the royal family, Buddhist monks, government officials, teachers, and elders. It is said that to show respect and proper manner, an educated person must acquire this formal standing position, which is recognized by all Thais. Informally among peers, Thais feel free to stand in any position comfortable to them. Leaning against walls or objects is considered a sign of laziness, however. 


\section{Chapter 4--Notes}

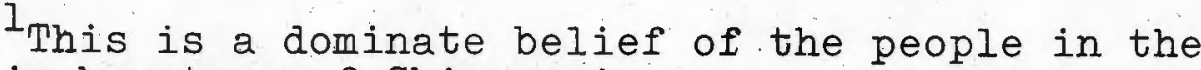
author's hometown of Chiengmai.

${ }^{2}$ Phillips (1974) has recorded that:

- . the attention given to controlling body movements is simply to emphasize for the child that people will decide whether he is good or bad on the basis of the way he handles his body, and he must therefore exercise extreme care in its use (p. 45).

3 For more detailed information consult "Kaanjyyn Le? Kaandosn (Standing and Walking)," Marraiaad Thai

( พาreinlna ) (Thai Etiquette), in Thai, pp. 2-10. 


\title{
CHAPTER V
}

MESSAGE THROUGH OBJECT AND USE OF ARTIFACTS

\author{
I. OBJECT IANGUAGE--FOUR
}

RELIGIOUS CEREMONIES

- . religion is the mainspring of behavior as manifested by the people.

Phya Anuman Rajdhon 1961, p. 65.

Ruesch and Kees (1974) have recognized that the study of object language has tremendous relevance to the field of anthropology:

Object language, because of its time-enduring qualities, plays an enormous role in archaeology, anthropology, and history (p. 190).

They have defined object language as:

Object Ianguage comprises all intentional and nonintentional display of material things, such as implements, machines, art objects, architectural structures, and--last but not least--the human body and whatever clothes or covers it. The embodiment of letters as they occur in books. and on signs has a material substance, and this aspect of words also has to be considered as object language (p. 189).

Since this study was conducted by means of an anthropological approach, i.e., the participant observation technique, it seems appropriate to use ritual objects used in four religious ceremonies to illustrate object language. The first and second rites to be discussed are widely and 
strictly observed in the northern part of the country during the celebration of the old traditional New Year--son kraan (สงกรนตั )--which falls between April 13 and April 15

annually. The other two ceremonies presented are faithfully observed by all indigenous persons of the entire country. Some additional data is also presented to illustrate Duncan's modality--use of artifacts. It is also related to Buddhism.

Scholars have observed the way in which participation by members of a society in religious ceremonies can sharpen perception, facilitate evaluation, or simplify actions of people. In coming to understand a cultural setting, Malinowski (1937, 1948) has observed the all-encompassing nature of religious ceremonials as:

Myth of magic [of religion, or any other body of customs or single custom] is definitely a warrant of its truth, a pedigree of its filiation, a charter of its claims to validity (p. 640).

He also states that:

Religion sets its stamps on the culturaliy valuable attitude and enforces it by public enactment ( $p .46)$.

The lod khro kaaw pun Ceremony

The lod khrs kaaw pun ceremony (ลดเคาระห์เก้า $\left.\right|_{b}$ ) is one of the northern traditional Thai ceremonies, performed at dawn of the fourth day (April 16) $)^{1}$ of the old traditional Thai New Year's celebration. This ceremony is a mixture of 
Brahmanism and folk Buddhism. It might be called an exorcism. 2 Each family has this ceremony performed for each person in the group. To have this ceremony performed is to help to inspire people's spirits to be ready to face another year. Thais wish to begin their new life with plenty of good omens, to have peace, to be contented with life. They believe that if the ceremony is performed, they will be blessed. Normally the mother in each family prepares the ceremonial objects (nine of each) in a banana bark tray divided into nine sections. The objects are items of consumption such as main dishes, dessert, fruit, selective clothing items belonging to all participants such as a shirt, and items to be sacrificed by burning such as the special sacred thread, fresh flowers, incense-sticks, and candles. 3

When all participants are present at the monastery, their male spokesman takes some flowers, incense-sticks, and candles, and goes to invite the abbot to descend and to begin the ceremony. When the abbot is present at the chapel, he will lead all participants to pay homage officially to Buddha and recite the five Buddhist precepts (siin haa ศaห้า) which belong to Buddhist laymen. Afterward, he chants the appropriate ceremonial passage from the Scriptures. When it is over, all participants take their ritual objects outside to be put right in front of the chapel. The oiled thread is lit and the clothing basket is turned upside down. Participants pick up ali clothing items and shake 
them vigorously to symbolize an act of chasing all bad omens from the participant's life. After the ceremony ends people believe that all the bad omens they may have will disappear throughout another entire year.

The Ceremonial Objects: Sacred Thread. This is thread of spun but untwisted cotton, with which every individual must measure the length between his stretched arms (left hand fingertip running through the chest to the right hand fingertip). After each individual's measurement is obtained, the sacred thread is coiled individually and soaked in coconut oil overnight. Each sacred thread is lit individually toward the end of the ritual. Its lighting ritual signifies the act of sacrificing which is meritorious and deeply related to the practice of Brahmanism.

Jack-fruit Leaves (bainun ใunkh). The northern word for jack-fruit leaf denotes the ideas of supporting, defending, maintaining, and enduring. The crucial significance is transferring the concept of "supporting" from the leaves to each individual through the individual's clothing item, which is arranged in a tray with these leaves. The name of the leaves may play a bigger role than the leaves themselves; and this may be why they are chosen for the ritual. Kam Leaves (baj kam quhis). The word kam means to reinforce. The leaves are arranged with the clothing items. The conveyed message is to reinforce an individual's life, which is done indirectly in a symbolic way. 


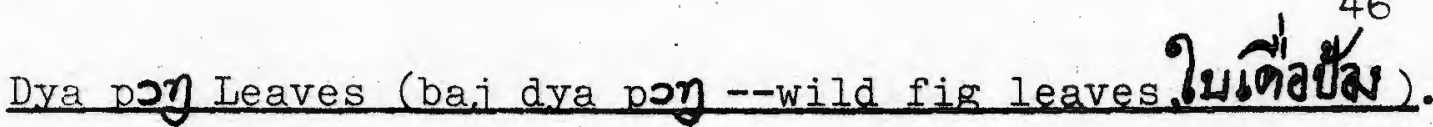

The word pDy in northern Thai means "to be free from," which is the essence used in this ritual. The individual's clothing items will receive this symbolic message from the leaves and transfer it to the individual who will be free from all bad omens throughout the new year.

Choos Leaves (baj choog qu fon). The northern Thai word choog means "luck" or "omens." The leaves signify "good luck" which will be brought to each participant throughout the year.

\section{Gew Leaves (baj keew Urbñ? $^{2}$ ). The word gew means} precious jewel. The leaves signify that each participant will gain plenty of material wealth, namely precious jewels. It is understood that the cultural concept of wealth symbolized as a precious jewel is desired by all.

Number Nine ( $\sigma^{N}$ leeg kaw (a)เก้า). The northern and central Thai word for symbolizes "progress, stepping forward and advancing." It is the most auspicious number. It is also strongly believed that this number is the highest and luckiest number of all (zero is nothing). In the world of meditation, it is believed number nine helps to lead any meditator to overcome all obstacles in this earthly world to achieve his meditative goal. Its Thai hierographic form appears on Buddhist medallions, hand bags, and other charms. Every item of ceremonial objects for this ritual and other similar ones, comes in nine. Other authors have repeatedly reported the use of number nine. 
Davis (1974) stated repeatedly the use of the number

nine but gave no symbolic meaning. He said:

- . the cultivator plants nine shoots of rice in the area before the goddess' shrine. While

he plants each of the shoots with his right hand,

he recited a stanza from a nine-verse religious chant in the sacred Pali language, the language of Thravada Buddhism. The rice shoots are said to be "nine siblings" (Kawton pii naung) ( $p .3$ ).

Phya Anuman Rajdhon (1961) revealed the number nine's original significance:

- . a single thread was too thin and easily snapped; hence either three or its square nine, the mystic number derived :from "the three Gems" or Buddhist Trinity, are made into one strand with ritualistic elaborations of process due to later development (p. 86).

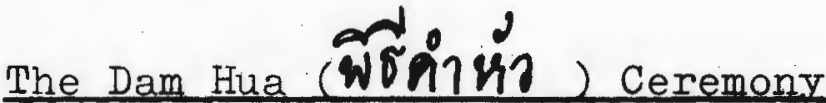

The old, traditional Thai New Year celebration begins at the first light of dawn on April 13 and lasts through April 15 officially, Its most widely performed ceremony is called dam hua (ดำหภ), which takes place on the third day. It is performed vividly in the northern Thai provinces, especially in the provincial city of Chiengmai. Participants will normally prepare several ritual items: the festival "lustrous water" in different metal water containers (silver, brass, or other materials, such as lacquerware, according to an individual's socio-economic status), fresh seasonal flowers, incense-sticks, tapers, and small inexpensive but practical articles which may be the produce from the participant's farm. These items will be offered to the individual being honored by the ceremony. 
The dam hua ceremony for the Buddhist monks is performed by members of local Buddhist monasteries; there will be similar ceremonies among the monks, and then ceremonies for the local government officials and elders in the community. Finally there will be ceremonies for the elderly individuals' kin, which are carried on among members of each family. Normally, all children who are away from their home will make a special effort to return home and participate in the celebration with their family, much like American families gather for the Christmas celebration.

Participants address the honored individual through a spokesman or by themselves in unison by formally and solemnly saying: "If any of our overt and/or covert acts and behaviors, which may have trespassed you throughout our communication, whether with or without deliberative intention, please be kind enough to forgive us, and let's start fresh from this day of the New Year. Please accept these humble articles which we bring you." ${ }^{4}$ The ceremonial objects are handed over and then the addressee dips one of his hands (usually the right hand which is the correct one for an auspicious rite) in the lustrous water and runs his wet hand through his hair to signify his acceptance of the reconciliation. ${ }^{5}$ This takes place after formal responsive words of pardoning, gratitude, and blessing. Thus any miscommunication is bridged and the communication process goes on. 
The dam hua ceremony is a traditional religious rite that is particularly interesting to speech educators because it seems to function as a communicative mediator in the atmosphere which lacks of verbalized feedback and inference checking in Thailand. However, feedback is emphasized by communication educators as being important in effective communication and this may be the Thai method of compensating for this lack. 6 People from this particular area appear to avoid raising questions, which sometimes is very important if miscommunication is to be prevented. Doubts are rarely verbalized, especially when communicating with the elders and persons of higher socio-economic status; instead they watch for nonverbal cues and depend heavily on their inferential and/or intuitional assumptions.? Perhaps this old traditional ceremony functions as a communicative mediator to repair known and unknown intracultural communication damages which may exist.

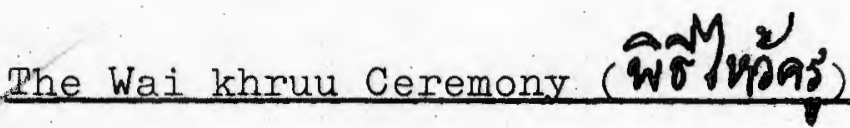

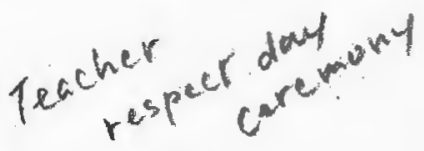

All Thai schools except colleges and universities; begin each academic year around the third week of May. This wai khruu ceremony ${ }^{8}$ involves religious rites, which students and teachers are obliged to perform sometime during the first term. Its metaphorical significance is unique to Thailand. This is among the important cultural behavioral patterns which belong to people in Thailand. 
The wis khruu ceremony is to pay respect and to honor a teacher. It must be performed on a Thursday which is declared as Teachers' Day. In a school, once a Thursday is designated as the wai khruu day, students must come to school with certain ritual articles. ${ }^{9}$ These include some of a special type of flower which bears the metaphorical meaning of being sharp as needles and possessing a desire to learn like the abundant seeds of its fruits; and incense-sticks and candles which carry religious connotation. The flowers and grass signify wisdom and sharpness belonging to both learners and teachers. 10

Once everyone is assembled at the school's auditorium, a group of Buddhist monks who have been invited, begin to give an appropriate chanting for the ceremony. ${ }^{11}$ Then students cite their learners' pledge. Student representatives from each class file in to pay respect to their teachers and to present them with the ceremonial articles. Buddhist monks conclude the rite by giving a chant of blessing. Beyond honoring their teachers, this ritual aims to strengthen the participants' spirits in order to help them to achieve a prosperous academic performance. Every child absorbs, learns, and is taught to exercise a profound sense of respect and obligation to his teachers. People in every profession possess this feeling running deep within themselves. Students, musicians, performers, boxers, and people in all professions perform this ceremony at least once a 
year. All Thai boxers and performers execute this unique ceremony each time they perform their act. They do it in the ring or backstage accompanied by the distinctive Thai boxing music but without music for the performers. This ceremony has been traditionally observed up to the modern era.

In the educational field, once the ceremony is performed, the academic year is believed to be blessed by a good omen. Students have a deep dedication to learning from their teachers who in turn are ready to reciprocate by teaching these students. Teachers have to carry on certain obligations to educate students. They try to live up to this expectation in order to deserve this kind of respect and honor from students. With this mutual commitment, both parties seem to establish a mutual ritual bond to try their best together to accomplish their goals. This behavioral pattern thus forms an unbreakable tie between students and teachers. Subsequently, as a result of whatever high academic achievements students may attain, their former teachers are placed even in a higher position to receive great respect and honor.

In this cultural behavior pattern we see how teachers are the most respected persons in Thai society, and they in turn highly prize their profession. 
The wi-sa-kha-bu-chaa celebration (610)(101)

The wi-sa-kha-bu-chaa is one of the most important religious celebrations among Buddhists in Thailand. It celebrates the great triple occurrences of Buddha's life: the day he was born more than 2500 years ago; the day he perceived "enlightenment" (the path leading to Nirvana or annihilation of being); and the day he entered Nirvana (the eternal life in which one stops being born, aging, sickening, and dying). It is the anniversary of these Buddhist triple events.

This celebration is observed in a special way by all Thai Buddhists. They normally go to offer food and receive blessing from Buddhist monks at their local monastery early in the morning of the full moon in the sixth lunar month. It usually falls in May but is in April some years. Devout Buddhists devote the whole day to observing laymen's monastic rules (siin pwa [ / to the monastery after eating their lunch, the last meal for the day, which must be eaten before noon. They recite all the precepts and spend the rest of the day practicing meditation. Likewise, monks take this opportunity to recite the 227 monastic rules that they have taken a vow to follow when they took refuge in the monkhood. They also give several sermons on Buddha's life episodes. Once the full moon is high, they lead all laymen in walking around 
the main chapel building clockwise three times to honor Buddha. 12 This is the high point of the event.

All participants in the procession carry some fresh flowers and lit incense-sticks and tapers in their hands. The hands are held in the wai position (erected and placed hands, palms inwardly together, held together below the tip of the chin). While walking, a special chant for the occasion is performed in unison. After they make three circumambulations, they reenter the chapel and pay homage to Buddha at the main altar. The hectic day is over at the monastery but not at home.

Upon returning home, they light the coconut oil lanterns which they had put up around the house on the fence poles earlier. Some persons always spend their time during the previous days decorating the gate and the fence with flowers and banana trees. Artistic ones paint their paper lanterns with scenes from Buddha's life. With the illumination from the full moon and the lanterns, each community is brightly lit. Once again the celebration of the great triple occurrences of Buddha's life has been observed by all people.

\section{USE OF ARTIFACTS}

\section{Phra ceedii (Pasoda Wrgเกิ์ย )}

Phra ceedii (sometimes appearing ceedii), pagoda, a memorial edifice with or without relics preserved inside 
(Hass 19'72), is an essential component of a Buddhist monastery. It appears in various forms as Phya Anuman Rajdhon (1961) has described:

They are roughly pyramidal in form, tapering to a plain or decorated tip and supported by a round or square base; bigger ones may rise from a terrace added for circumambulatory purposes (p. 65).

Rajdhon (1961) observed that its original purpose was as ". . a tumulus containing relics of Buddha, but the smaller ones in many instances have been built to contain the cremated bones of some deceased persons" ( $p .65)$. According to the same author, "It is the Buddhist. Thai custom that a corpse be cremated and the incinerated bones and ashes deposited in Phra ceedii . . This is equivalent to the Christian custom of burial beneath a cross in consecrated earth". (p. 65).

\section{Phra ohud tha ruub (Buddha Image Wy Uwhr50)}

Buddha images are one of the important objects to Thai Buddhists and are also the essential component of a Thai monastery. Every Thai household has at least one Buddha altar if not an entire room full of Buddhas. It is at the altar or in this room where all members of a household assemble to practice meditation and/or to pay homage to Buddha, sometimes twice daily, early in the morning and at night before retiring.

In a monastery, Buddha images are enshrined in the wi-haan (วนาr), the central chapel where the congregation 
assembles to attend the religious rites, a bood (Uสn'), the sacred chapel (off limits for female but not to male) where monks twice daily assemble to recite their vow and the monastic rules (precepts), and in the monks' residence. Normally every Thai Buddhist carries small Buddhas (sómetimes medallions, or amulets) around in his shirt pocket, wallet, or on a necklace (like Christians wear a cross) as an indication that he is a Buddhist and perhaps to reassure himself that he is well: protected from any possible harm, such as being hurt in an accident.

Buddha images are made of precious metal such as gold, silver, brass, jade, emerald, animal bone (such as elephant tusk), and a hard wood, such as teak wood. The images are always in the form of typical Buddha's most significant historical actions, for example, walking on the seven lotus flowers, stopping a demon with his right hand, ${ }^{13}$ sitting with his knees apart and legs crossed under in a state of bliss. However, the facial expressions and proportions and craftsmanship depend on an individual artisan's artistic talent; and some of these artists spend their lifetime devoting their creative ability to making Buddha images. Consequently, there are many variations in style, which seem to reflect and represent each artisan's artistic ideas.

Several procedures are involved in creating a Buddha: the materials are carefuliy examined and selected at an auspicious time of day; the most suitable style is chosen. 
After the image is made a complicated nonstop (sometimes seven days or longer) religious rite takes place to sanctify the new Buddha. With the last procedure a Buddha becomes our tangibly spiritual protector.

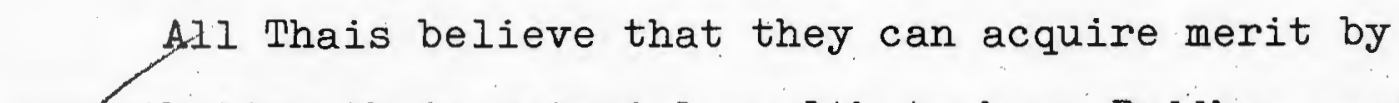
contributing their material wealth to have Buddhas, medallions, and amulets created on auspicious occasions such as when a new chapel or monastery is constructed, a high ranking monk is installed or cremated, and other occasions like these.

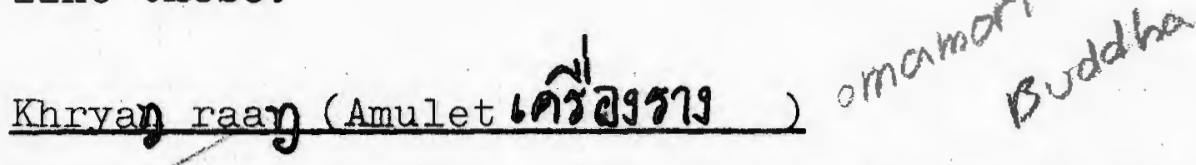

Almost all villagers including young children, possess amulets--many of them in the form of Buddha images--for good luck, protection (from ghosts, sorcery, or thieves), or to avoid illness or accident. The worth, i.e., power, of an amulet is largely determined by the "knowledge" of the person (often, but not always a monk) who has sanctified it. Specific amulets may become so highly reputed that they are beyond valuation in economic terms, although this rare. More commonly, the villager carries amulets which he hopes will further his purposes, but in which he has no abiding faith (Piker 1973).

\section{Takrud (Dte gkroot njn\%n)}

McFarland's perfect description of takrud (his spelling is dta gkroot) is: 
- . "magic jewelry," charms or amulets. These consist of hollow brass, lead of silver cylinders containing small tightly rolled pieces of cloth, marked with cablistic designs, symbols and letterings. These are strung on a small cord and worn around the waist; or to protect the wearer against injury from all forms of weapons (1969, pp. 349-350).

The word "amulets" is misleading and misinterpreted. Thais associate this word with a Buddha image more than the word takrud.

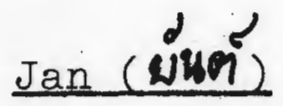

Jan is a mystic drawing with magical letters inscribed in the spaces on a metal plate, written on a piece of cloth, paper, or leather, and sometimes painted on gable-ends of houses (McFarland 1969). Before it is used formally it has to be pronounced or consecrated with sacred formulas. Usually an elderly learned man is able to creat a jan and perform the sacred rite.

Jan is recognized as a charm which provides its owner (wearer) with protection from all forms of bad omens. Jan is posted on the first pole (the most auspicious pole of every house, which is called saw ?eeg เ人่าban; saw--pole, and ?eeg--prime) and on every pole when a new house is constructed, on the top of the gate, and on the main door of a house. It is carried around in a purse and wallet. Perhaps it comforts its carrier with an intrinsic assurance of being safe from all possible harm. 


\section{CLOTHING (COLORS)}

\section{Yellow}

Shed thou householders' finery As coral tree its leaves in fall; And going forth in yellow clad, Fare lonely as rhinoceros.

Conze 1971, p. 81.

In general, colors of clothing communicate nonverbally, especially in Thailand. Saffron (yellow) color is dominately the color of Buddhism: the Thai Buddhist flag is yellow; Thai Buddhist monks wear saffron (yellow) robes; and all Buddha images always appear in yellow (gold) either because of the natural yellowish color of the materials they are made out of, or because they are covered or coated with gold leaf. and finally robed with the saffron robes.

\section{$\underline{\text { Khaki }}$}

Khaki color represents the government. Governmental officials, civil service employees, teachers, and policemen wear khaki uniforms. In all government schools, kindergarten through high school, male students wear their khaki shorts with white, short sleeved shirts.

BIue

Female students wear loose, dark blue, knee-length skirts with white short sleeved blouses. Sometimes, female teachers wear their dark blue skirts with white or other plain, light colored blouses. 
The three colors of the Thai national flag and their distributions are: blue, signifying the nation; white signifying the religion (Buddhism, which is also "holy" and/of "pure"); 14 and red, signifying the monarch. Every Thai student learns these colors' correlations by heart in school.

$\underline{\text { Red }}$

Before leaving a northern Thai (specifically in the Chiengmai area) cremation at a crematorium, every guest normally receives a piece of red thread besides a gift, which is traditionally a pamphlet or a book. The red piece of thread represents a good luck charm; and especially the red color signifies good luck. It is said that one needs a good luck charm after one goes through a place like a crematorium.

\section{Daily Color}

Auspicious colors are associated with the days of the week. They are: Sunday--red; Monday--yellow; Thesday-pink; Wednesday--green; Thursday--orange (a shade of a ripe betel nut); Friday--blue; and Saturday--purple. Thai females used to be more conscientious in wearing outfits in these various colors accordingly because each color is auspicious on its certain day. However, only a few of the younger generation still follow this tradition of choice and even fewer of them pay attention to the colors' implications. For example, purple is not allowed to be the color of the bride's 
wedding garments nor any decorative household items, such as curtains. Purple in Thai is called sii-muay ( also associated commonly with sii-soog (6) 6 (6n--chartreuse;) and their identical implication denotes sorrow, sadness, and grief, which are considered "unfit" and "inauspicious" for the occasion. Black, white, and their combination are not accepted on certain occasions, such as weddings, birthday parties, or a housewarming party. This is because they are associated with mourning and denote a subdued atmosphere. Nevertheless, most of the northern Thai males and females wear white shirts and blouses, and dark if not black pants and ankle length skirts when they attend religious functions at a monastery.

\section{Black and White}

Black is the mourning color among Thais. Every Thai female wears a black outfit throughout the mourning period, 100 or 365 days. Sometimes an individual Thai male wears a black arm band at the funeral when he wears Western garments (official suits and ties); otherwise there is no restriction on how he has to dress himself in mourning.

Thai Buddhist nuns wear white outfits consisting of narrow white ankle length skirts and plain long sleeved, collarless blouses. The outfit is not different from the Chinese female mourners' outfits, except Chinese prefer white baggy pants more than a narrow white ankle length skirt. Thai nuns shave their heads and eyebrows. 
Chinese (or Chinese-Thai) male and female mourners wear white garments for at least the first 100 days if not a longer period after the death of an immediate member of their family. Sometimes, some orthodox males are supposed to have their heads and eyebrows shaved and are not supposed to have another haircut or shave throughout the mourning period. However, some unorthodox males mourn in white outfits but leave their heads and eyebrows unshaved (in normal condition). When the mourning is over, females normally wear black or black and white outfits for a while longer; and males resume wearing their regular clothing but with a black arm band or a little piece of black cloth pinned on a shirt sleeve.

\section{ORIENTATION TO DIRECTIONS}

Staircase Positions

Bochner (1974) has described the Thai vernacular architecture as:

Thai vernacular architecture reflects a rural society with a relatively low degree of occupational roledifferentation. The house provides quarters for the family, but also functions as a storage complex for grain, and has shelter underneath for cows, chickens, and other domestic animals. . . Thai houses have visual. but not auditory privacy. Houses nearby are usually owned by relatives, a system of land tenure that is very supportive of a social organization based on the extended family system. (p. 13)

Most Thai houses are unpainted, of semidark stained wood. They are dull and look as if they are unfinished in 
comparison with American houses. They normally are built with open space between the ground and the floor. Therefore, a typical northern Thai house has at least one outside staircase, in the front, which is built attached to the house from the ground. In general, a house staircase can descend at any point of the compass except to the west, which is called thid ta wan tog (nhryyjum), denoting the direction of the sun's falling off and/or setting. 15 If the situation is unavoidable, a staircase must be divided into two parts; the upper one may face the west, and the lower part must be angled and turned towards any direction other than the west.

The northern Thai people are very sensitive to words' denotations if not to their connotations. Therefore the psychological and intrinsic rationale behind this cultural practice may be that they simply avoid living with the notion that their staircase leads them to the direction where the sun daily sets, as if so does the dweller's life.

\section{COOKING}

The exotic aromas of all Thai food is very foreign to most Americans. To produce such aromas, ingredients such as coconut milk, hot chili pepper, several kinds of tropical spices and herbs, shrimp paste, crab paste, fish sauce, soy sauce, or raw, pickled fish are used in Thai cooking. 
Preservation of the natural flavor of meat is not emphasized in Thai cooking. Meat is sliced very thin and small and is always well cooked with flavoring ingredients as mentioned. Individually cut vegetables, which are cooked sparingly just before the dish is served, are always included. Iesser amounts of meat but more vegetables and spices seem to be the basic ratios of Thai cooking. It is completely different from American cooking.

It takes a considerable effort for a typical American to appreciate Thai cooking. The taste is too spicy for the American palate, which prefers food less spicy and with a real meat flavor. Generally, Americans consume more meat than Thais whose main staple is rice. Nevertheless, they pay attention to the balancing of food values like Americans do, but prefer to consume less meat and occasionally have meatless meals.

\section{Breakfast}

A typical American breakfast consists of coffee; juice; chicken eggs; ham, bacon, hash (beef), or sausage; buttered toast, sweet roll, hashbrowns (potato), oatmeal, hot cereal, or cold cereal; fresh fruit in season, dried fruit, stewed or canned fruit. If you ask a Thai, you will get a different version of what breakfast is.

A regular breakfast on a normal weekday consists of either steamed or boiled rice with heated leftovers and a simple additional dish of greens and meat. 
On weekends breakfast is more or less like a regular dinner. It requires longer hours to prepare and all members of the family to participate. Normally, one member of a family gets up and goes to buy some frésh meat, vegetables, and other cooking supplies from the nearest open market, on a bike or on foot, around six or seven o'clock in the morning. One usually spends about an hour or so to get everything on his mother's daily grocery list. Meanwhile, the mother or one of the brothers or sisters, will get up and get a charcoal burner started. Once it starts, rice will be steamed or boiled. While rice is cooking, other things are supposed to be prepared, such as getting all spices ground in a grinding-stone with a stone or wooden pestle. One uses only one hand while grinding and uses the other free hand to shield around the grinding-stone to avoid any spilling. Grinding normally takes about half an hour before all spices are well ground and are ready to be used in the main dish. Traditionally, the mother or one of the oldest sisters takes care of the proportion of each kind of spice and other ingredients of each recipe. The primary preparation is finished by the time the shopper returns from the market. Upon his arrival, meat and vegetables will be washed and prepared for the main dish. Meat is sliced very thin and small; vegetables are cut into an individual bite. Everyone helps in this painstaking process. Children are allowed to participate in any capacity of what they are 
capable. Even the head of the household, the father, always participates as a taster! Through the whole process, a lively conversation always dominates, echoing over the grinding and/or cooking noises. Of course, the final result of this painstaking process is the serene moment of enjoying their labor at the table (or on the floor) quietly. After the quiet feast is over, all brothers and sisters will put every piece of leftover food away, clean the table, and wash all the dishes.

In the writer's home there are no servants; most householders do the chores, which include cooking, themselves. This provides a marvelous opportunity to interact. Something that would be missed if there were servants. This is how Thais learn to share a certain responsibility through childhood; from this working together. This is part of several unbreakable and cohesive bonds which bind Thai families tightly together.

\section{Eating}

Among Thais, eating takes place sitting on the floor with the food placed on mats or trays. Eating is the happiest of activities. It must be carried on in serenity; therefore talking is absent during meals. There are no fixed seating places; everyone sits wherever he pleases. However, one is encouraged to maintain an erect torso, sitting with both legs folded on one side, and chewing carefully and quietly. 
Everyone has an individual rice plate in front; and other food dishes are shared by all, placed in the middle. Sweet rice is normally served in the northern Thailand, Chiengmai. It is glutinous and comes in palm leaf baskets and is shared by everyone. One must make a small ball out of the glutinous rice before dipping it in food and placing it into one's mouth. There are forks and spoons when regular rice is served. 


\section{Chapter 5--Notes}

Normally the fourth day is called wan paag pii (gutind) which usually falls on April 16, according with the local Iunar calendar. as he wrote:

${ }^{2}$ Davis (1974) recognized the rite as rites of exorcism

- . in rites of exorcism (song khau), the ritual specialist carries and deposits the harmful forces of pollution away to the West ( $p .12)$.

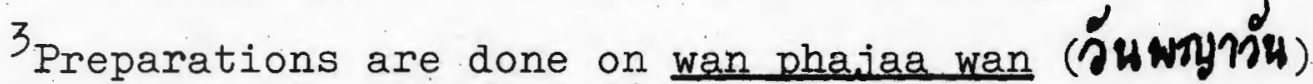
which usually falls on April 15.

${ }^{4}$ Davis (1974) in trying to prove a different theory has recorded a different version of the communique. Only a response from the addressor was recorded as:

The importance of knowing high from low is stressed during the New Yeal festival, when young people make formal requests for the blessings of their elders. In reciting his blessing, the elder says, "If you have ascended to low places or trodden upon high places, I now forgive Jou" (p. 15).

${ }^{5}$ Dam hua refers to the act or process of washing or cleansing hair in the northern dialect. After the dam hua ceremony, addressers use the addressee's "lustrous water" to wash hair.

$6_{\text {The Thai social structure is a structure of vertical }}$ organization which consists of superordinates and subordinates. It's communication process is the one-way communication. Subordinates are like children (sometimes): "they are seen but not heard." Also, seriority has a permanent place in Thai society. Davis (1974) suggests:

Probably every language known has some way of expressing superiority in terms of height.

Psychological studies indicate that vertical

discrimination may be a more fundamental form of perception than lateral discrimination (p. 15).

${ }^{7}$ Steward (1971) has stated one example, that is:

- another contrast to the American idea of confrontation is found in many societies such as Thailand in the use of a third party. Business may be conducted with another person by means of 
an emissary and not directly in a face-to-face confrontation of the principles involved ( $p .49$ ).

${ }^{8}$ Phillips (1974) interpreted the wai khruu ceremony by quoting Frostu:

Briefly it is hypothesized that every adult organizes his social contact . . . by means of a speech form of contractual relationship. These contracts are informal, or implicit, since they lack ritual or legal basis. [This is not completely free for Bang Chan. There is, for example, a special "Teachers' Day," sanctioned by the national government, set aside for honoring teachers, and thus providing ritualistic reinforcement to the contract]. They are not based on any idea of law, and they are unenforceable through authority; they exist only at the pleasure of the contractants. The contracts are dyadic in that they occur only between two people; three or more individuals are not brought together, . . although spouses often honor the obligations inherent in each other's contracts ( $p .94$ ).

${ }^{9}$ See Phya Anuman Rajahon, Iife and Ritual in Old Siam (New Haven: HRAF Press, 1961), pp. 80-81.

10 darg khem ( $92 \pi$ เ the genera Ixora, Pavetta, or Duperrea (Hass, p. 65). p. 394) jazg makhya (ดวกมะเ์ )--flowers of eggplant (Hass, Bermuda grass, dub-grass, a creeping grass of all parts of the tropics (McFarland, p. 901).

12 "Clockwise" is used because the occasion is an auspicious rite.

13 This specific image of Budgha is known as phra phud

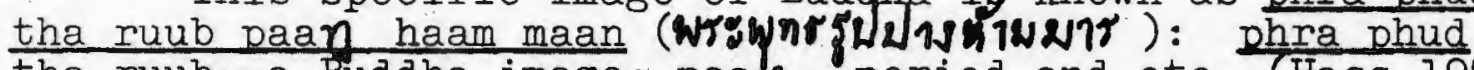
tha ruub--a Buddha image; paay-period and etc. (Hass 1972 , p. 319); haam--to stop and etc. (Hass, p. 584); maan--Mara, chief demon (Hass, p. 401).

${ }^{14}$ Davis (1974) has stated also that ". . White is associated with Budahism . . ." (p. 18).

15 However, the east--thid ta wan? 029 (ท̆́n:jualn) and the north--thid nya ( auspicious directions. Phya Anuman Rajdhon (1961) has related that "The image of the Buddha is usually placed facing east or north" (p. 84). 
CHAPTER VI

MESSAGE THROUGH PARAIANGUAGE

\section{THAI IINGUISTIC PARALLEL TO PARALANGUAGE IN THAILAND}

Language is a complex set of bodily habits. We have individually characteristic manners or ways of communication. These varied aspects of communication are called paralanguage.

Takahashi 1972, p. 80.

In presenting "Thai paralanguage," only one aspect, "vocal intensity" is discussed because it carries the most subtle nonverbal message in the Thai daily communication. Subsequently, out of awareness, Thais transfer and emit this cultural norm in intercultural communication. Miscommunication begins because the Thais' counterparts-Westerners who neither comprehend nor are aware of this distinctive norm--do not practice or share this aspect of Thai nonverbal communication. Thais are very uncomfortable when they encounter their counterparts' loud vocal quality. On goes the miscommunication. 


\section{VOCAL INTENSITY (LOUDNESS AND SOFTNESS)}

- . paralanguage deals with how something is said and not what is said.

$$
\text { Knapp 1972, p. } 7
$$

Vocal qualifiers. This includes intensity (overloud to oversoft), pitch height (overhigh to overlow), and extent (extreme drawl to extreme clipping).

Trager 1958 , p. 6.

When Thais speak or discuss things formally and informally, they utter in a very soft and gentle voice and manner. They are deliberately taught that speaking in a soft voice is the only way to show the good and appropriate manner of a cultivated individual. In general people judge whether one is "good" or "bad" on the basis of the voice qualities of one's vocal utterances and how he delivers them. A loud voice is normally associated with "market mouth" which refers to the voice belonging to uncultivated (uncouth) people. It also indicates a typical emotion of anger, fear, joy, or in argument of confrontation, which should be under a self-disciplinary control. "Vocal quality (tone of voice) refers to one's language, and one's language refers to one's family origin," is a Thai proverb which seems to recapitulate this aspect of vocal quality of the Thai paralinguistic behaviors. Phillips (1974) also states that "They (manners) define, in a social if not in an ontological sense, the 'good' or 'bad' person" (p. 46). 
When first hearing Western peoples, Thais are very apprehensive and question why Westerners are impolite and unfriendly. Westerners seem to them to speak loudly and to be constantly angry or in confrontation. This is an intercultural misunderstanding due to the vocal intensity used by Westerners and is opposite to what a typical Thai has been taught from his childhood. If a Thai happens to contact a Westerner who talks with normal (for him) vigor and animation, the Thai will withdraw and not wish to associate with the Westerner. He also interprets that the Westerner is unfriendly and must be avoided. He may be (or as a matter of fact "is") a "bad" person. This attitude stems from one of several traditional sayings, which states that "a loud person is a 'bad' person and brings 'bad' omens to himself and his associates."

It seems that Thais use an individual's vocal quality of loudness and/or softness as one of several criteria to judge a person's "goodness" or "badness." Every Thai child is familiar with this aspect of proper behavior which is in

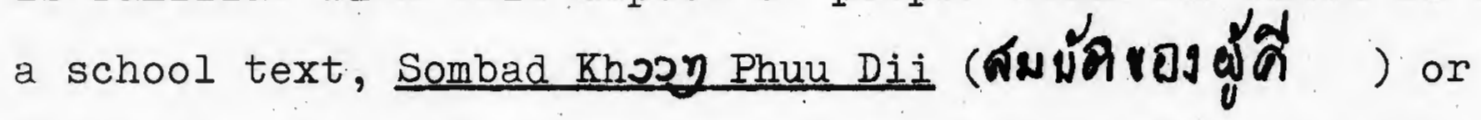
Characteristics of a Good Person (Ministry of Education, 1959). The text is one among several texts which are used at home and in school to instruct every child in proper behavior and morality. Children are constantly told that a loud voice definitely drives away "good" omens from the speaker and his associates. At home, if he speaks loudly, 
he will be reminded sternly that his family's internal affairs will be vulnerable to all his neighbors. Bochner (1975) has observed that ". . Thai houses have visual but not auditory privacy" (p. 13). He is encouraged to see that is avoided.

It is very difficult for a Thai to learn that people from different cultures are not supposed to be interpreted or judged by this Thai moral code. To Thais it is almost inconceivable to comprehend that a loud person can be friendly or "good" in nature. Unless this idiosyncracy is explained, he certainly will find that this is a stumbling block in intercultural communication, which cannot help but increase cross-cultural miscommunication. 
CHAPTER VII

MESSAGE THROUGH PERSONA工 AND SOCIA工 DISTANCE

I. PROXEMICS

The Thai "point of view" concerning the presence of Americans in Thailand has been widely published. It is hardly surprising that the visitors are viewed critically. But the American reader would like to discover the reasons underlying Thai disapproval. When several versions of recent antiAmerican commentary were compared, this reader was surprised to discover that the common, most damning, and universally condemned bit of behavior was credited to American soldiers, and it consisted of varied forms of body contact with Thai girls "on the streets" or in other public places. Apparently many Thai perceive overt physical interaction as a more serious offense than our dismupting the national economy of Thailand by an avalanche of men, money, and materials!

Howell 1968, p. I.

Hall's (1966) four categories will be used as a convenient means in presenting the Thai proxemic behaviors. These categories are:

1. Intimate Distance--Close Phase This is the distance of love-making and wrestling, comforting and protecting. Physical contact or the high possibility of physical involvement is uppermost in the awareness of both persons.

Far Phase--six to eighteen inches.

2. Personal Distance--Close Phase one and a half to two and a half feet. Far Phase--two and a half to four feet. 
3. Social Distance--Close Phase

four to seven feet.

Far Phase-seven to twelve feet.

4. Public Distance--Close Phase

twelve to twenty-five feet.

Far Phase--twenty-five or more (pp. 117-124).

In Thai society the sexes are publicly segregated.

Therefore a section on male and female social positions has been added to Hall's categories. Thais make a rigid distinction between the two directions--right and left--which are also separately dealt with.

\section{Infancy}

- . the human child has immense potentialities which give rise to his idiosyncratic awareness and perception of the world (life-private world), always patterned by his tradition, with a highly idiomatic personal code for communicating and receiving and interpreting messages from the world and from other persons.

Frank 1973, p. 124.

As the infant matures into adulthood he gradually acquires a picture of the world he inhabits and his place within it. Pervasive orientations--of trust or suspicion, of affection or hostility-are learned early, often at considerable pain, and through communication with significant other people... Such cognitive predispositions are learned unconsciously, and most people are only vaguely aware of their profound effects.

$$
\text { Barnlund 1973, p. } 6 \text {. }
$$

Thais' general proxemic concept is one of male and female segregation. Thai infants of both sexes grow up 
together, however, until reaching their teens, and then they are molded into a segregated environment. Smith (1968) says :

In general the young child is treated permissively. It is nursed whenever it cries, is weaned and toilettrained gradually, and is often fondled (p. 125).

Thai parents provide physical closeness to their infants of both sexes equally. They are held in their parent's arms more than the Western infants are. One of the parents if not both quickly picks up and holds the infant, very often with a hug, caress, and a "nose-kiss--ho2m (นวม )" that is used colloquially to signify a kiss, whenever they are around their infants. "Nose-kiss" is definitely a technique of kissing which seems to be an amusing behavior to nonThais. Nose is used instead of lips when a kiss is planted on the forehead, nose, chin, or cheeks. However, certain bodily components such as infants' palms, are not supposed to be kissed. 1

From infancy till their early teens, Thai children of both sexes mingle freely with each other with close physical nearness (Hall's "Intimate Distance"). However Smith (1968) has reported an earlier segregation, ". . at about 4 the children begin to play with their age-mates in the village. They soon segregate into sex groups and roam freely through the village". (p. 126). They go to school, from kindergarten up to fourth grade together and spend all their social and leisure hours together. Not until well past their early 
teens, are they transferred to a segregated school. Their social life also becomes segregated at this time as boys and girls start to associate socially with peers within the same sex. A proxemic boundary of the sexes emerges and becomes a distinctive behavioral norm in the eyes of Westerners.

\section{Late Childhood and Adolescence}

Since Thai boys and girls of the same age groups mostly attend segregated institutions, their proxemics shows the greatest closeness among the same sex. Boys sit and stand close together, hold hands, put their hands around each other's shoulder or waist, and constantly touch and caress each other. So do girls among themselves. Embree (1950) reported:

While two friends do not walk in step they do maintain psychic contact by holding hands or by one holding a finger or two of the other. This is common action among young men as well as young women, but not, traditionally, of a young man and a young woman (p. 183).

Hass (1972) has explained this behavior as:

kiawk2i (kan) (เกี่ยวกอ้นกัน ) $v$ to hook each other's little fingers (of lovers or intimate friends of the same sex, esp. w.) (p. 4l-42).

Phillips (1974) has observed and interpreted the behavior as:

Most Thai, particularly members of the same sex, thoroughly enjoy expressing their mutual affection through bodily contact: by holding hands, grasping the leg or arm of the other, and in Bang Chan, sometimes by sleeping with one another. In the last instance, there is absolutely no sexual contact; often during the cold season the practice serves not only friendship but the additional purpose of keeping the participants warm. However, the items underscore 
the fact that touching carries important social connotations and the toucher should be cognizant of these, and beware of what he does; should he touch the wrong person in the wrong way, for example, a social superior to whom he should be expressing respect rather than camaraderie, he will be identified as ill-mannered or uncouth (pp. 45-46).

These typical behaviors are interpreted as "proper and appropriate" in schools, at home, and wherever they happen to be. They probably fit Hall's (1966) proxemic category of the "intimate distance--close phase" (p. 119).

\section{Adulthood}

\& Thai men and women observe strict cultural norms of seniority, socio-economic status differences, and sex. When they communicate with people who are different from themselves in the aspects mentioned above, they must maintain their proxemic distance. These distances are at least from $1-1 / 2$ to 4 feet (parents, teachers, Buddhist monks, and local governmental officials), and from 4 to 12 feet (nonlocal and high governmental officials, members of the royal family, and the royal family). (Hall's Social Distance and Public Distance.)

When associating with persons of equal status or strangers in public, Thais care very little about their physical closeness, for example, in situations such as waiting in lines, on conveyances, onlooking at the scene of an accident, and other similar situations. They normally pay no attention to the proxemic distance while waiting in line for public transportation such as a bus, or while 
being served as in a store or theater. They have very limited concepts of waiting until one's turn arrives, and the "first come, first served" concept. Their proxemic behaviors here fit with Hall's Intimate Distance--Far Phase, 6 to 18 inches. Hence, age, ${ }^{2}$ sex, rank, and status play a significant role in influencing Thai proxemic behavioral norms which have been described.

\section{Male and Female Public Position}

The monks sit in a row according to seniority in age and rank in the brotherhood. A special place has been prepared for them, arranged so that their right shoulders face the altar where a Buddha image is installed.

Phya Anuman Rajahon 1961, pp. 84-85.

Right and left sides are designated as the social positions of male and female respectively. Males are always on the right side and females on the left. A photograph of the King and queen side by side is found commonly hanging high on a wall of the living room if not of every room. The photograph shows clearly the social and cultural positions of male and female, that the King is on the right of the Queen. If the photographs are two separate ones, the King's will be on the right of the Queen's. In public appearances, they strictly observe this specific cultural norm.

Male and Female Sleeping Positions

At wedding rites and receptions, the groom must always stand or sit on the right, and the left belongs to the bride. 
The traditional sleeping arrangement between a married couple, is that the husband must sleep on the right and the wife sleeps on the left. They must also sleep with their heads toward any direction except the west--thid ta wan tog, where the sun sets. 3

The right direction is equated with the north--thid nya (ทिศเหน̂d); and the left is associated with the south-thid taai (ทิศ 9 \%ั). Thid nya implies the superior position; and thid taaj indicates the subordinate position (Davis 1974). However, this cultural implication seems to suggest that it is proper and appropriate for a married couple to behave this way. It is not because of people's vicious discriminative biases. Davis (1974) states:

Psychological studies indicate that vertical discrimination may be a more fundamental form of perception than lateral discrimination (p. 15). 


\section{Chapter 2--Notes}

It is said that if infant's palms are kissed, the specific infant will acquire a tendency of thievery when it grows up. However, there is not logical rational which can be found.

${ }^{2}$ Smith et al. (1968) has confirmed that:

The basic respect-prestige pattern of Thai culture, based on age differentiation is instilled at this time (p. 126).

${ }^{3}$ Davis (1974) has observed that "a person sleeps with his head to the east and his feet to the north" (p. 12). 


\section{CHAPTER VIII}

\section{MESSAGE THROUGH OLFACTION}

\section{Artificial Scents}

Due to the tropical temperature and humidity, after bathing, Thais like to cover their entire bodies with nam ?ob thai (น́pวนไทย), scented water (similar to a cologne) which is a mixture of perfume and body powder. Within a few minutes in a cool breeze, their entire bodies are soothed, scented as well as covered with white powder. Normally, tropical flowers like jasmines provide soothing fragrances. The fragrance and white body powder used by Thai males may give the impression of being somewhat feminine to Westerners. Thais make no distinction between feminine and masculine fragrances. Sometimes Thais appear in public while their faces are covered with white spots from this perfume, and consequently, nonnatives tend to think that those individuals are a little bit strange.

To sooth their thirst from the hot temperature, Thais

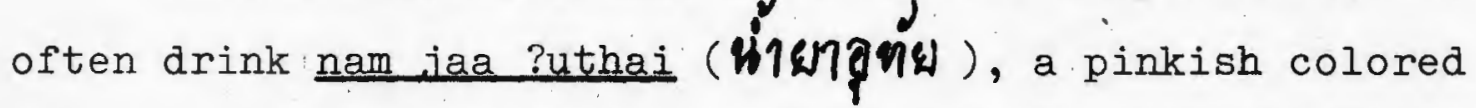
and scented water (Phillips, 1974). Hosts serve it to their midday guests upon their arrival without any inquiry. Some families fill water jars outside their gate with nam jaa ?uthai for all thirsty travellers and wanderers as a form 
of meritorious act. The water is served in all functional activities, such as sport events, during a hot day. Thais believe that the scent and not the psychological effect of the pinkish color helps to soothe the thirst. They also imply that the water is a medicine which cures the thirst by calling the mixture jaa (medicine) ?uthai.

Fragrance from jasmines is also very popular among Thais. At dawn they wash their faces with jasmine water, made by putting a few fresh jasmine flowers in fresh, cool water from a well. They also put jasmine flowers in syrup which is served with coconut meat or fruits as a dessert. They dry the flowers and keep them among their clothing. They also use them to make incense-sticks to be used in paying homage to Buddha. They associate fragrances with "goodness." Therefore they use fragrant flowers, incensesticks in al:l meritorious and religious activities.

\section{Natural Body Odors}

\section{khon dii taaj hosm: khon leew taai men}

The good person's death is fragrant:

The bad person's death is reeky.

This old saying seems to indicate that Thais associate "goodness" with fragrance and "badness" with bad odor. It is a concept that Thai parents transfer to their children at an early age. At dawn, after rising, and at dusk, before the 
sun sets, Thai children are trained strictly to bathe. They are also encouraged to wear old clothing as long as it does not smell.

If a Thai is a good and popular person, he is given a label as having "fragrant name" (chyy ho2m favaม); on the other hand, if he is a bad person, he is labeled as having

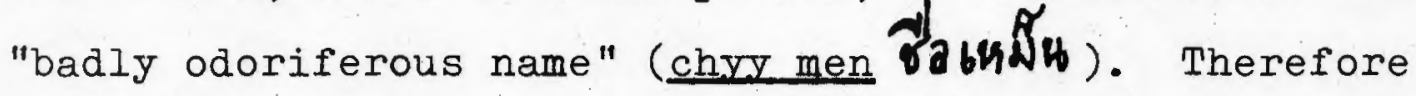
every Thai strives to live according to moral codes and hopes to achieve a good reputation, "fragrant name."I 


\section{Chapter 8--Notes}

$I_{\text {To }}$ understand the association of these terms, Phillips (1974) has offered this explanation:

Ask most villagers: "What kind of a person is so-and-so?" and their replies will consistently be in terms of whether he is "bad" or "good," rather than in terms of non-evaluative descriptions; e.g., he is "funny," "passive," "interesting." The words khon majdii and khon dii ("a bad person" and "a good person") and two of the most frequently occurring items in the Thai lexicon. One might epigrammatically characterize much of the villagers' thought as "super-ego-dominated." That this mode of thought should be applied to many of the SCT [sentence complete in text] situations is hardly unexpectable (p. 136).

Stewart (1971) has stated a similar view:

A Peace Corps representative from Washington went to Thailand to appraise the effectiveness of his volunteers. When he asked the Thai supervisor about the Thai instructors of English, the answer was likely to be, "Well, Mr. A. is an excellent instructor, and Mr. B. is a good instructor (or a poor instructor") thereby giving the American representative an absolute judgment. The instructor was judged against a quality of goodness in being a teacher.

The example is important because the Thai supervisor gave a different kind of answer when asked about the American Peace Corps volunteers teaching English alongside the Thai instructors. He observed that: "Mr. Smith is as good as (or worse than) Mr. Jackson." In other words, he switched to the typically American comparative style of making judgments when evaluating Americans.

It is important to stress that the Thai used two kinds of judgments, illustrating the thesis that there is no particular psychological or cultural characteristic adhered to by all members of a given ethnic group. Variation is the very essence of culture and any culture contains all, or nearly all human possibilities ( $p$. 24). 


\section{CHAPTER IX}

\section{MESSAGE THROUGH SKIN SENSITIVITY}

\section{Touch}

Since women are regarded as the major obstacles to any man's renunciation of the sensory world female members of the laity must be particularly circumspect in their dealings with bhikkhus

[Buddhist monks], taking care to avoid all physical contact even of an indirect nature. One of the implications of this avoidance is that a woman who has occasion to pass any object--such as a book, or a glass of water--to a monk, must place it, not in his hand but upon a cloth (pha phrakhen) which he carries for the purpose. Furthermore, on all the trains and buses special seats are reserved for members of the Sangha, to minimize the risk of their coming into contact with female passengers.

Bunnag 1973, p. 36.

It is a taboo for an adult male to touch a female publicly in the Thai society. However, touching one another among members of the same sex is not prescribed with respect to the Thai cultural norm. It is quite typical to witness Thai male or female intimates constantly touching each other, and sometimes hold hands, while they are engaging in a formal or an informal conversation. Their mannerism indicates the close relationship, moral support, assurance, or approval among the individuals involved. It also communicates genuine sincere feeling from one person to 
inother. Tf this norm is violated, by male and female adults holding hards with each other, the parties involved are punished by being stared at. Staring is a sanctional form of behavior which is normally considered as an improper mannerism. Sometimes, a more severe sanction, a verbal assault, is aimed directly towards the involved parties. Finally, if they seem to be stubborn, they will be told that they probably inherit this bad mannerism from their families. When the individuals' families are tarnished, consequently it is a matter of life and death because Thais worship and guard their families' names with their lives. Therefore, causing one's family to be a subject of a cynical criticism is a severe form of social and cultural shaming that one must avoid.

\section{Yemperature}

Living in the tropical climate almost all year round, Thais are very sensitive to both hot and cold temperatures. The King, Queen, and, royal family are protected from hot sun by a sabpaton (ด̆لทh ; a silk, embroidered, longhandled umbreljt, borne as an insignia of rank) (McFarland 1969). Among Thai Buddhist monks, an umbrella is one of a few stipulated items, which is considered a necessity (Bunnag 1973). They use an umbrella to protect themselves from hot sun and cold monsoonal rain when they travel on foot. Thai farmers (males and females) usually dress themselves with long sleeved shirts and blouses, and pants and 
ankle length skirts while working in the hot and wet rice fields, besides wearing wide-winged palm leaf hats. At the famous Thai floating market; every female merchant wears this type of hat while paddling her produce canoe in a canal. The wearing of hats is a common sight among rural students but is no longer among the urban students. The former normally go to school in the hot sun on foot but the urban students have the privilege of using a bus, which eliminates the necessity of the wearing of hats.

When monsoon rain falls in Thailand it is sometimes a big, cold shower. Then it usually prevents people from working outdoors or travelling until it stops raining. When it only rains lightly, it keeps no one from using either an umbrella or a hat to carry on his outdoor business.

Westerners witnessing a Thai male carrying an umbrella in a light rain or seeking shelter from a shower, may interpret this behavior as effeminate. As for Thai females, they carefully protect their complexions from the tropical sun because having light and smooth skin is considered to be more attractive than having darker skin. It is commonly known among Thais that Thai males also prefer ladios whose complexions are lighter like tesy rom bai ( 6 Mง ช้ม thy--melons; rom--to be shaded; and bai--leaf: "Melons are shaded under leaves." 1 


\section{Chapter 9--Notes}

$l_{\text {This preference can be proven if it is searched }}$ through Thai classical literature, poetry, or songs. It is expressed when males serenade females. 


\section{CHAPTER $\mathrm{X}$}

\section{IMPLICATIONS}

In general Siamese, considerably more than Occidentals, tend to be aware of physical bearing, beauty, and ugliness, as well as the use of the body as a communicative device. A person's physical appearance is an indication of his character, particularly his moral nature, and kinesthetic modes are explicitly used for conveying love, regard, and as suggested above, disrespect.

$$
\text { Phillips 1974, p. } 45 .
$$

On the basis of the Thai NVC descriptive data it seems apparent that Thais communicate nonverbally more than Westerners. Phillips' (1974) passage concurs with the findings of this study. The findings are rules of behaviors related to Thai NVC.

From the descriptive behaviors of Thai NVC, descriptions of Thai personality may be drawn. However, the most conclusive and precise description of Thai personality was already described by a Western-trained Thai psychologist for the Cornell Thailand Handbook as Phillips (1974) quoted:

The psychologist commented that the Thai in general were hospitable people; that the tempo of their lives was slow; that they possessed considerable equanimity; that many Thai actions had a basic in the Buddhist religion; that the Thai respected age; that the Thai, although capable of making rapid culturaladaptations at least on a superficial level, were basically conservative; that ritual and ceremony were important parts of Thai life; that the 
Thai were not steadfast; that they were extravagant; that they were bashful, introverted; that they were not socially minded, that is, they were not joiners; that the Thai approach to life's concerns was empirical rather than theoretical; that the Thai were indolent; that they were egoistic, self-centered; that they lacked persistence, "stick-to-it-iveness"; and that the Thai were a mild people, a nonviolent people (pp. 46-47).

Westerners may use the descriptions as a guideline in communicating with Thais. It is important to emphasize that they must be used with extreme caution. Redfield (1973) has suggested:

- . in any community people live partiy in terms of what they think ought to be and partly in terms of what actually is. The two are not always in close correspondence, and in certain societies (as witness the Kinsey report) the two things may be far apart . . . I suggest that there is at least one other dimension to the social life: the expectations of what one is likely actually to encounter in life (p. 44).

Suggestions for a further study of Thai NVC include (1) to prove whether or not the Buddhist religion governs behaviors of Thai NVC, and (2) to investigate other rituals and ceremonies related to Thai NVC as Condon (1966) has viewed:

Ritual is sometimes described as the behavioral part of a mythology. The mythology may be for almost any purpose, but consistently it emphasizes a sense of community among its members and a sense of permanence. To participate in a ritual is to participate in a community, often one that claims a tradition of centuries ( $p .101$ ). Since some of these behaviors are Thais' overt behaviors, they are the measure of Thais as Phillips (1974) 
suggested, ". - the fact that overt behaviors alone in the measure of man, . ." (p. 4l).

It is important to emphasize that "the measure of man" is the measure of the indigenous people who themselves are familiar with and use these overt behaviors. Therefore the intracultural communication is safe. However, Westerners are familiar with their own overt behaviors but not the Thais'; there exists a problem in intercultural communication. This is why these findings will be some value in the field of intercultural and cross-cultural communication.

Through the descriptions of Thai NVC, it is clear to agree with Phillips' (1974) statement, ". . there exists for all Thai a relatively explicit and unquestioned set of standards of what is proper, desirable, or appropriate behaviors" (p. 40). Since the statement has been proved to be true through this study, it may be true in another culture also. Therefore more researches in this field need to be carried on in order to provide a better means of communicating for all members of intercultural and crosscultural communities. The findings from this research will help people who wish to enhance their intercultural communication, which is the most important part of the communication-the most important process of all human beings. 
Austin, William M. 1971. "Nonverbal communication," in Culture, class and language variety. Edited by A. I. Davis. Ill.: NCTE.

Barna, LaRay M. 1975. "Stumbling blocks to intercultural communication," in Reading in intercultural communication. Edited by David S. Hoopes. The Regional Council for Intercultural Education. Pittsburgh, Pennsylvania: University of Pittsburgh, 1: 25-35.

Barnlund, Dean C. 1973. "Communication: the context of change," in Basic reading in communication theory. Edited by C. D. Mortenson. New York: Harper and Row.

Benedict, Ruth F. 1952. Thai culture and behavior: an unpublished wartime study dated september 1943. Reprinted as Data Paper No. 4, Cornell University, Southeast Asia Program, Ithaca, New York.

Birdwhistell, Ray I. 1970. Kinesics and context. New York: Ballantine Books, Inc.

Bochner, Stephen. 1975. "The house form as a corner stone of culture," Topics in Culture Learning, 3: 9-20. Honolulu: East-West Center.

Bruyn, S. T. 1966. The human perspective in sociology. Englewood Cliffs, New Jersey: Prentice-Hall, Inc.

Bunnag, Jane. 1973. Buddhist monk, buddhist layman: a study of urban monastic organization in central Thailand. Cambridge, England: Cambridge University Press.

Condon, John C. 1966. Semantics and communication. New York: The Macmillan Co.

1973. "Nonverbal communication," in Human Relations in Cultural Communication. Series C, Teacher Training Materials. New Jersey: Rutgers Graduate School of Education.

Conze, Edward. 1971. Buddhist scriptures. Harmondsworth, Middlesex, England: Penguin Books. 
Davis, Flora. 1974. "How to read body language," in Messages: a reader in human communication. Edited by Jean M. Civickly. New York: Random House.

Davis, Richard. 1974. "Tolerance and intolerance of ambiguity in northern Thai myth and ritual," Ethnology, 13 (1): 1-24.

Duncan, Starkey Jr. 1969. "Nonverbal communication," Psychology Bulletin, 72 (2): 118-137.

Ekman, Paul. 1975. "Face muscles talk every language," Psychology Today, September: 35-39.

Embree, John E. 1950. "Thailand: a loosely structured social system," American Anthropologist, 52: 181-193.

Fast, Julius. 1970. Body language. New York: Pocket Books.

Frank, Lawrence K. 1973. "Tactile communication," in Basic reading in communication theory. Edited by C. D. Mortenson. New York: Harper and Row.

Fortes, M. 1953. "The structure of unilineal descent groups," American Anthropologist, 1: 22.

Hall, Edward T. 1959. The silent language. Greenwich, Conn.: Premier Publishing Company.

1966. The hidden dimension. Garden City, New York: Doubleday and Company, Inc.

Hass, Mary R. 1972. Thai-English student's dictionary. Stanford, California: Stanford University Press.

Howell, William T. 1968. "The study of intercultural communication in liberal education," reprinted from Pacific Speech, 4: 1-8.

Lopez, Annette M. 1973. "Nonverbal communication across cultures: using Puerto Rican nonverbal communication through storytelling to enhance English comprehension of Spanish-speaking Puerto Rican children," Ph.D. dissertation, Temple University.

Malakoon, Pii (M. L.). 1974. "Kaanjyyn le? kaan dəən (standing and walking)," Maarajaad Thai (Thai Etiquette) in Thai. Bangkok, Thailand: Ministry of Education of Thailand. 
Malinowski, B. 1973. "Culture," in Encyclopedia of the social sciences. Edited by Edwin R. A. Seligman. New York: The MacMillan Company. Vol. 4.

1948. Magic, science and religion and other essays. Glencoe, Illinois: The Free Press.

McFarland, George B. 1969. Thai-English dictionary.

Stanford, California: Stanford University Press.

Mehrabian, Albert. 1974. "Communication without words," in Messages: a reader in human communication. Edited by Jean M. Civickly. New York: Random House.

Ministry of Education of Thailand. 1959. Sombad khory phuu dii (characteristics of a good person). In Thai. A Handbook for Teachers Instructing in Proper Behavior. Bangkok, Thailand.

Pack, Alice C. 1973. "Interpretations of kinesics are cultural not universal," TESOL Reporter, 6: (1, 2, and 3). Laie, Hawaii: English Language Institute, The Church College of Hawaii.

Phillips, Herbert P. 1974. Thai peasant personality. Berkeley, California: University of California Press.

Piker, Steven. 1968. "The relationship of belief systems to behavior in rural Thai society," Asian Survey,

8: $384-399$.

Powdermaker, Hortense. 1966. Stranger and friend. New York: W. W. Norton Company, Inc.

Rajdhon, Phya Anuman. 1969. Iife and ritual in old Siam. Translated and edited by William J. Gedney. New Haven: HRAF Press.

Redfield, Robert. 1973. The little community and peasant society and culture. Chicago, Illinois: The University of Chicago Press.

Ruesch, J. 1966. "Nonverbal language and therapy," in Communication and culture. Edited by A. G. Smith. New. York: Holt, Rinehart \& Winston.

, and Kees, W. 1974. Nonverbal communication: notes of visual perception of human relations. Berkeley, California: University of California Press. 
Sapir, Edward. 1964. Culture, language, and personality: selected essays. Edited by D. G. Mandelbaum.

Berkeley, California: University of California Press.

$\checkmark$ Scheflen, Albert E. 1964. "The significance of posture in communication system," Psychiatry, 27: 316-331.

Singer, Marshall R. 1975. "A perception approach," in Reading in intercultural communication. Edited by David S. Hoopes. The Regional Council of Intercultural Education. Pittsburgh, Pennsylvania: University Of Pittsburgh, 1: 11-24.

Smith, Arthur L. 1972. "Interpersonal communication within transracial contexts," in Intercultural communication: a reader. Edited by Larry A. Samovar and Richard E. Porter. Belmont, California: Wadsworth Publishing Co., Inc.

Smith, Harvey H., et al. 1968. Area handbook for Thailand. Washington, D.C.: U. S. Government Printing Office.

Stewart, Edward C. 1971. American cultural patterns: a cross-cultural perspective. The Regional Council for International Education. Pittsburgh, Pennsylvania: University of Pittsburgh.

Takahashi, Genji. 1972. Studies in communication. Tokyo: Eichosha.

Tyler, Stephen A. 1973: India: an anthropological perspective. Pacific Palisades, California: Goodyear Publishing Company, Inc.

Useem, Hohn, Useem, Ruth, and Donoghue, John. 1963. "Men in the middle of the third culture: the roles of American and non-western people in cross cultural administration," Human Organization, 22: 169-179. 
APPENDIX 


\section{IEEGEND ON THE TRANSIITERATION OF THAI}

\section{Phonemes}

Consonants: Bilabial Dental Palatal Velar Glottal

stops: Vd. Unasp.

V1. Unasp.

V1. Asp.

$\mathrm{b}$

p-

ph-

d

$t-$

th-

c-

ch-

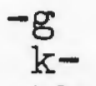

$\mathrm{kh}-$

spirants :

$$
\text { VI. Unasp }
$$$$
\text { f- }
$$$$
\text { s- }
$$$$
\text { h- }
$$

sonorants:

Vd. Semivowels

Vd. Nasals

Vd. Lateral

W

m

n

1-

r-

Retroflex

Vowels:

Front

Unrounded

High

Mid

Low i, ii, ia $y, y y$, ya

e, ee

0,66
ว, 22

$a, a a$ $y$

Back

Rounded

u, uu, ua

0,00

0,20 